Article

\title{
Seasonal changes in size and mite-prevalence of a bee colony exposed to dinotefuran via pollen paste and damaged by Varroa mites
}

\author{
Toshiro Yamada \\ Graduate School of Natural Science \& Technology, Kanazawa University, Kanazawa, Ishikawa, Japan; \\ yamatoshikazu0501@yahoo.co.jp
}

Simple Summary: The impact of dinotefuran (DF) administered via pollen paste on the bee colony damaged by Varroa mites was investigated. Seasonal changes in the number of adult bees, that of capped brood and the mite-prevalence on adult bees were measured through the field experiment for 180 days. It was found that the bee colony was collapsed by the intake of a smaller amount of DF due to the synergistic effect of DF and mite-damage. From the fact that the daily pesticide-free sugar-syrup intake per bee in the DF-exposed colony administered via pollen paste is greater than that of the control colony, DF may have an appetite-promoting effect. Since the consumption of DFcontaining pollen paste per bee per day is almost no difference among all colonies, DF seems to have no repellent effect. Mite-prevalence continues to rise and becomes almost $100 \%$ near the time of colony extinction. The inner-temperature-fluctuation-range of the hive-box $\left(\mathrm{T}_{i}\right)$ is smaller than that of the ambient temperature $\left(T_{a}\right)$. The inner-temperature-fluctuation-range of DF-exposed-colony hive-box is larger than that of control-colony hive-box. If $\mathrm{T}_{\mathrm{a}}$ is $30^{\circ} \mathrm{C}$ or less, $\mathrm{T}_{\mathrm{i}}$ becomes higher than $\mathrm{T}_{\mathrm{a}}$, if $\mathrm{T}_{\mathrm{a}}$ is $30^{\circ} \mathrm{C}$ or more, $\mathrm{T}_{\mathrm{i}}$ becomes lower than $\mathrm{T}_{\mathrm{a}}$.

\begin{abstract}
Neonicotinoids, such as dinotefuran (DF), have caused a variety of problems, such as massive loss and winter failure of the bee colony, as a price for the benefit of reducing farm work, because it continues to maintain a high insecticide activity over a long period of time. In this study, a field experiment was conducted for about six months to investigate the effects of DF on bee colonies damaged by Varroa mites. This study examined the long-term changes in such as the size of bee colonies, the intake of sugar syrup (SS), intake of pollen paste (PP), which is a vehicle for administering DF, the intake of DF, the mite-prevalence of bees and the inside and outside temperatures of hive-boxes. The variation width of the inner temperature of the hive-box is less than that of the ambient temperature $\left(\mathrm{T}_{\mathrm{a}}\right)$. The inner temperature of the hive-box is adjusted with about $30{ }^{\circ} \mathrm{C}$ of $\mathrm{T}_{\mathrm{a}}$ as the boundary. If $\mathrm{T}_{\mathrm{a}}$ is lower than $30^{\circ} \mathrm{C}$, the inner temperature of the box is higher than $\mathrm{T}_{\mathrm{a}}$, and if $\mathrm{T}_{\mathrm{a}}$ is higher than $30^{\circ} \mathrm{C}$, it is lower than $\mathrm{T}_{\mathrm{a}}$. The temperature variation width of the DFexposed colony is greater than that of the control colony. The average intake of SS per bee per day of the DF-exposed colony is more than that of the control colony. The average intake of PP per bee per day of the DF-exposed colony is almost equal to that of the control colony. These results suggest that bees do not avoid DF, and ingest PP without distinction between toxic and pesticide-free. In the period from the start of DF administration to the colony extinction, the intake of DF per colony is about $865 \mu \mathrm{g} /$ colony, the intake per bee is $14 \mathrm{ng} / \mathrm{bee}$, and the intake per bee per day is less than 0.1 $\mathrm{ng} / \mathrm{bee} /$ day in this work. These intakes are much lower than the previous ones $(60-65 \mathrm{ng} / \mathrm{bee}, 0.27-$ $2.32 \mathrm{ng} / \mathrm{bee} /$ day). These discrepancies may be because attacks of mites and Japanese giant hornets hastened the colony collapse. Seasonal changes in mite-prevalence of honeybees is approximately the same regardless of the bee colonies. At the end of August (the start of attacks by Japanese giant hornets), the mite-prevalence will increase rapidly. Even if the number of bees damaged by mites turns to decrease, the mite-prevalence will continue to increase, with approaching $100 \%$ before bee colonies become extinct. In this study, it was found that the bee colony was collapsed by the intake of a smaller amount of DF due to the synergistic effect of DF and mite-damage. To prevent a bee colony collapse, not only to make an effort to minimalize the adverse effect on the bee colony of
\end{abstract}


neonicotinoids such as DF with long-term residual effect and high insecticide properties, it is necessary to reduce the damage of mites as much as possible, while considering the synergistically adverse effects of neonicotinoids and miticides.

Keywords: seasonal change; honeybee; adult bee; capped brood; Varroa mite; colony size; dinotefuran; neonicotinoid; mite-prevalence; field experiment

\section{Introduction}

Neonicotinoid pesticides invented at the end of the 20th century were strongly suspected from laboratory-level experiments as the cause of the large-scale bee colony loss that occurred in the 21st century. Some scientists argued that laboratory-level experiments did not necessarily reproduce the phenomena occurring in actual beekeeping. In order to dispel this doubt, in an environment that approximates the actual beekeeping place, long-term field experiments have revealed the following issues on a honeybee colony; the possibility that neonicotinoid pesticides can cause the colony collapse disorder (CCD) [1-3]; the differences in the impact between sugar syrup (SS) and pollen paste (PP) containing a neonicotinoid pesticide [4]; the differences in the impact between neonicotinoid pesticides and organophosphorus pesticides on honeybee colonies [5,6]; the differences in the impact of pesticides between the mite-existing region (Japan) and the mite-free region (Maui) [7]; the differences in the impact of pesticides between the region with clear seasonal changes (Japan) and the region with no seasonal changes (Maui) [7,8]; and the impact of neonicotinoid pesticides on the winterization of honeybee colonies [9].

According to the field experiment, all neonicotinoid-exposed colonies became extinct $(100 \%$ extinction rate), but the extinction rates of the control colony and the organophosphate-exposed colony were about the same each other and they were much lower than the neonicotinoid-exposed colony $[4,5,7]$. From these field experiments, neonicotinoid pesticides, which have a strong insecticidal activity and long-term residual effect, are presumed to cause serious damage to the bee colony and sometimes collapse the bee colony.

It is known, for not only such neonicotinoid pesticides but also external parasitic mites such as Varroa mites, to greatly reduce the activity of honeybee colony. So far, there have been many reports on damage to honeybee colonies by pests such as Varroa mites, wax-moth larvae and small hive beetles.

There have been many reports on the effects of the ectoparasitic mite Varroa destructor and the deformed wing virus (DWV) closely associated with the mite, which can seriously damage honeybee colonies and sometimes collapse honeybee colonies, on honeybee colonies as follows: The impact of Varroa mites on honeybee colonies were being investigated around the world [10]: Switzerland [11], southeastern Brazil [12], South Africa [13], Mexico [14], southern Spain [15], northern Iraq [16] and so on.

The cause of the mass loss and overwintering failure of the mysterious bee colonies that occurred in the world's apiaries in the early 21st century was tried to be determined, and it was presumed that Varroa mites (DWV) would be one of the causes of the loss of those honeybee colonies [17-20].

Then, there have been reports on Varroa-mite-damage prevention measures [21-27]. The damage situation of bee colonies by pests other than the Varroa mite was investigated and countermeasures against those pests such as the small hive beetle [28-34] and the wax moth larva [35-40] were reported.

Furthermore, investigation and research of bee viruses that can weaken the honeybee colony or occasionally collapse the bee colony has been carried out. In order to understand the infection status of the bee virus in the world, extensive literature survey on the geographic distribution of major viruses (DWV, acute bee paralysis virus, sacbrood virus, etc.) infecting bees Apis mellifera was conducted and their temporal population dynamics were reviewed [41].

On the other hand, field experiments were conducted in a Varroa-mite-free area to counter the theory that the cause of the mass loss and wintering failures of honeybee colonies was not neonicotinoid pesticides but mites. Experimental results in Maui and Australia without Varroa mites 
have concluded that the massive loss of honeybee colonies is caused by long-term residual pesticides with high toxicity such as neonicotinoid pesticides rather than Varroa mites [7,8,42]. These results suggest that neonicotinoid pesticides are one of the main causes of mass loss in the honeybee colony.

We have previously revealed through long-term field experiments that the neonicotinoid pesticides dinotefuran and clothianidin have a serious adverse effect on bee colonies [1,4-8]. However, the effects of neonicotinoid pesticides on bee colonies damaged by Varroa mites have not been clarified during field experiments. This study examines the effects of the neonicotinoid pesticide dinotefuran (DF) on honeybee Apis mellifera colonies damaged Varroa mites, which have not been reported so far, through long-term field experiments.

\section{Materials and Methods}

\subsection{Materials and Preparation of Pesticide Concentrations}

Starkle Mate® (10\% DF; Mitsui Chemicals Aglo, Inc., Tokyo, Japan) was used in this study.

\subsubsection{Preparation of SS}

Granulated sugar was purchased from the Japan Beekeeping Association (http://www.beekeeping.or.jp/), which is composed of $99.7988 \%$ of purified sugar (granulated sugar); Sodium chloride (salt) $0.1 \%$ or more; L-lysine hydrochloride $0.1 \%$ or more; food dye (Blue No. 2) $0.0012 \%$ or more). $20 \mathrm{~kg}$ of granulated sugar and $13.33 \mathrm{~kg}$ of hot water of about $75{ }^{\circ} \mathrm{C}$ were mixed in a 50 L plastic tank, and then $60 \%$ SS of granulated sugar was made.

\subsubsection{Preparation of SS Containing DF for Toxic PP}

$1 \mathrm{~kg}$ of 100 ppm-DF-SS was made using SS containing $60 \mathrm{wt} \%$ of sugar and Starkle Mate® $(10 \%$ DF; Mitsui Chemicals Aglo, Inc., Tokyo, Japan). Prepared SS containing DF in a 10 L-container was blocked the light with a black bag and stored in a refrigerator.

\subsubsection{Preparation of PP without DF}

$25 \mathrm{~kg}$ of pollen made in Spain was purchased from Tawara Apiaries Co., Ltd., Kobe, Japan (https://tawara88.com/about.html). Pollen was used after it was lightly ground with a flour milling equipment "Kona Ace A-7" manufactured by Kokkousha Co., Ltd., Nagoya, Japan (http://www.kokkousha.co.jp/). The viscosity of PP is determined by the ratio of SS in PP, the particle size of pollen and the temperature of PP. Therefore, the ratio of pollen and SS that does not fall even if the PP filled in the tray is turned upside down was preliminarily examined. As a result, pollen $60 \%$ by weight, SS $40 \%$ by weight was confirmed to be an appropriate ratio. Pesticide-free and PP containing $0.4 \mathrm{ppm}$ of DF was prepared by $10 \mathrm{~kg}$, respectively. Pesticide-free PP, put $6 \mathrm{~kg}$ of pollen and $4 \mathrm{~kg}$ of SS (pesticide-free) in a large plastic bucket, with a drill screwdriver with stirring blades used for high viscosity, was prepared by kneading at a low speed until a uniform paste.

\subsubsection{Preparation of PP without DF}

PP containing dinotefuran, in the same manner as in the case of pesticide-free, was prepared. By adding $40 \mathrm{~g}$ of $100 \mathrm{ppm}$-DF-SS into $3960 \mathrm{~g}$ of pesticide-free water, $4 \mathrm{~kg}$ of 1 ppm-DF-SS was prepared, where 100 ppm-DF-SS and 1 ppm-DF-SS mean sugar syrup containing 100 ppm and 1 ppm of dinotefuran, respectively. $10 \mathrm{~kg}$ of 0.4 ppm-DF-PP was prepared by kneading $6 \mathrm{~kg}$ of pollen and $4 \mathrm{~kg}$ of 1-ppm-DF- SS, where 0.4 ppm-DF-PP means pollen paste containing $0.4 \mathrm{ppm}$ of dinotefuran. Incidentally, DF concentration in PP in this work (0.4 ppm-DF) was set to about $70 \%$ of the dinotefuran concentration 0.565 ppm in PP in 2011/2012 experiments [4].

\subsubsection{Preparation and keeping of tray filled with PP}

The PP of $300 \mathrm{~g}$, while weighing in the upper plate balance scale (accuracy $\pm 1 \mathrm{~g}$ ), was packed into a foamed polystyrene tray. Then, the PP tray filled with pollen paste was wrapped to prevent 
evaporation of moisture from the tray and stored in the refrigerator to prevent alteration of PP. Incidentally, pesticide-free PP tray in the refrigerator compartment, PP tray containing DF was stored in the freezer compartment.

\subsection{Long-Term Field Experimental Method}

\subsubsection{Experimental Site and Arrangement of hive-box}

The experiment was conducted at a place (Latitude $37^{\circ} 2$ ' '35" N; Longitude $136^{\circ} 45$ '38" E; 70 m above sea level) with a house about $3.5 \mathrm{~km}$ away in the north-northwest direction from the experimental site that had been carried out so far $[4,5,6,7]$. It was leveled so as to be weeding and flat experiment site in advance. Six hive-boxes for experiments, the entrance is about $80 \mathrm{~cm}$ intervals in the south direction, towards the west to the east, three control colonies (CR-1, CR-2, CR-3), then, three DF-exposed colonies (DF-1, DF-2, DF-3) were arranged. It should be noted that each hive-box is placed on a stand of about $20 \mathrm{~cm}$ in height, and a large pvc tray (many $3 \mathrm{~mm}$ perforated) protruding greatly from the entrance side of the hive-box in front is placed between the hive-box and the stand, where many holes in the tray is to prevent water from accumulating in the tray for the measurement of the death bee number.

\subsubsection{Preparation for Field Experiment}

Number the inner walls and bottom of the hive-box used in the experiment. At this time, toward the front of the entrance, number clockwise on the wall and the bottom is described as "Bottom" (Supplementary Figure S1). Add a symbol on both sides of the comb frame from the left toward the front of the hive-box (Supplementary Figure S2) so that if you take a picture, you can identify the object, where the left and right sides of comb frame toward the entrance of the hive-box are called "F" (front) and "B" (back). For an example, "CR-2-3B" means the right side ("B") of the third comb frame ("3") in the second control-colony hive-box ("CR-2").

The experiment began on June 19, 2018 using eight hive-boxes consisting of four comb frames with honeybees. Until July 1, 2018 without pesticide administration, the state of each honeybee colony was observed. Selected 6 colonies that appeared to be similar conditions from among the eight prepared colonies, the experiments of pesticide (DF) administration) were started on July 1, 2018, where three colonies were DF-exposed colonies and three colonies were pesticide-free (control) colonies. The remaining two colonies that were not used in the experiment were spares when an accident occurred in the experimental colony. It should be noted that all the queen bees in the eight colonies were used for sisterhood. We began to conduct an observation experiment about every two weeks from July 1, 2018. In the observation experiment, taking photographs of all the comb frames with and without honey bees and the hive-box with honeybees, and counting the number of dead bees, the observation results were recorded. Furthermore, into all honeybee colonies were fed $800 \mathrm{~g}$ of SS (pesticide-free), pesticide-free PP of 300g was fed into three control colonies (CR-1, CR-2, CR3), and PP of $300 \mathrm{~g}$ containing $0.4 \mathrm{ppm}$ of DF was fed into three DF-exposed colonies (DF-1, DF-2, DF3).

Incidentally, before the start of the experiment from June 19 to July 1, the average intakes of SS and PP of the honeybee colony was measured in order to reduce the remaining amounts of SS and $\mathrm{PP}$ as much as possible. The amounts of SS and PP to be fed to each colony every observation experiment were determined to be $800 \mathrm{~g}$ and $300 \mathrm{~g}$, respectively. In addition, the remaining amounts of SS and PP were accurately measured with an upper plate balance, respectively, and were recorded each time at each observation experiment.

Since thus controlling the feeding amounts of SS and PP, the remaining amounts were often zero. If there is a remaining amount, the PP containing 0.4ppm of DF after measurement, once, was decided to be stored in a thick plastic bag. Incidentally, the remaining PP was $4912.6 \mathrm{~g}$ in total amount, which is equivalent to $2 \mathrm{mmg}$ of DF. After completion of the experiment, a hole of about $50 \mathrm{~cm}$ in diameter and about $50 \mathrm{~cm}$ in depth was dug between the trees in the central part of the site (about $825 \mathrm{~m} 2$ ) owned by Toshiro Yamada, and the DF-containing PP was discarded in it, and the hole was 
filled back. After the measurement, all the participants of the experiment checked the experimental status and recorded what they noticed in the research note. In addition, until the time when the whole bee colony was collapsed, or if it succeeded in overwintering, we decided to conduct an experiment until mid-April.

\subsubsection{Procedures and Instructions of Field Experiment}

The most important data are the number of adult bees and the number of capped brood. In order to obtain these data as accurate as possible. 1) The honeybee outside the hive-box is as small as possible. In order to achieve this, we started the experiment immediately after dawn (The start time of the experiment is determined by referring to the sunrise time. The experiment starts at 5:30 a.m. from July to September, and at 6:00 a.m. from October onwards.). 2) When you pull out a comb frame with bees one by one to take a picture, it is to prevent bees from taking off. In order to do so, we gently pulled out the comb frame calmly and set the comb frame with bees in a photography stand (Supplementary Figure S3) that we made in advance and take a photo. 3) Bees may become restless due to wind and rain, so bad weather conditions should be avoided. Using the weather forecast, etc., the experiment is carried out to avoid the day of bad weather as much as possible. On the day, if the weather suddenly worsens, the experiment date will be changed. Under the above precautions, a field experiment which has uncontrollable factors are performed by the procedure shown in Supplementary Method S1 in order to obtain the experimental data as accurately and correctly as possible.

\subsection{How to count the number of bees, the number of capped brood and the number of bees damaged by mites}

Using the photograph taken as described above, it is possible to determine the number of adult bees, the number of capped brood and the number of mite-damaged bees. Counting these numbers from the photographs taken is an extremely difficult task. Therefore, with the cooperation of Mr. Yoshiki Nagai of Nanosystem Co., Ltd., Kyoto, Japan (http://nanosystem.jp/firm.htm), which develops image processing software, in 2012, we first developed a computer software that automatically counts these numbers from photographic images, and has since made improvements. The accuracy and operation of the count have been greatly improved by the improvement so far. These counting work significantly has been improved on the count time and count accuracy compared to the amount of work that was counted by hand directly from the original photo.

There is still a problem, however, that these counts are inaccurate because of bee overlap, outof-focus images, extreme contrast differences in the image, misjudgment of counting target and so on. In this computer software, it is also possible to correct manually after automatic counting. Therefore, after automatic counting, the count mistakes in the automation, while zooming in the image, are corrected by manual operation and the corrected number becomes the final data. Thus, in automation, there is still a problem to improve this computer software, but manual operation of this computer software, it is possible to correct the count error in the automation. The improvements of the counting accuracy and speed by this computer software have contributed greatly to the improvement of the data analysis accuracy and the speed in our long-term field experiments. An overview of this automatic counting system is shown below.

2.3.1. Computer Software Developed to Assist in Accurately Counting the Numbers of Adult Bees, Capped Brood and Mite-Damaged Bees

This computer software was developed to count the numbers of adult bees ad capped brood accurately. Therefore, we will explain how to count the number of adult bees existing on the image of comb frame and how to count the number of capped brood using the image read. These numbers are counted with a computer software using the image as which a photo is imported into a computer. The number of adult bees in a colony is obtained by summing up the numbers of adult bees of both sides of all the comb frames with bees and the number of the remaining adult bees in the hive-box without comb frame. The number of capped brood in a colony is obtained by summing up the numbers of capped brood of both sides of all the comb frames without the bee. The number of adult 
bees damaged by the Varroa mite can be obtained from the same photo as which is used to count the adult bees. How to count bees damaged by the Varroa mite is described in a separate section. Incidentally, the measurement results obtained by such a method, as long as the image remains, it can be verified by anyone at any time. Here, limited to the number of adult bees and capped brood of the comb frame, the determination procedure of those numbers will be described in Supplementary Method S2.

\subsubsection{Counting Method of the Number of Adult Bees Damaged by Varroa Mites}

Sampling method of Varroa mites in a honeybee colony, such as sticky board method, ether roll method and powder sugar shake method, has been reported so far [43-45]. In either method, it is impossible to know the total number of Varroa mites in the bee colony. Mite on the bee's back Mite on the drone's Mites on the bee's leg \& back

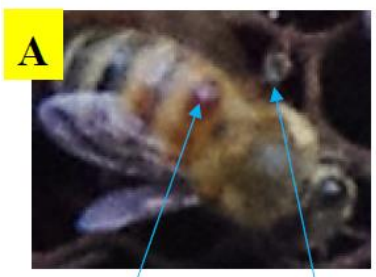

Mite

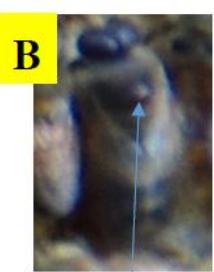

Mite

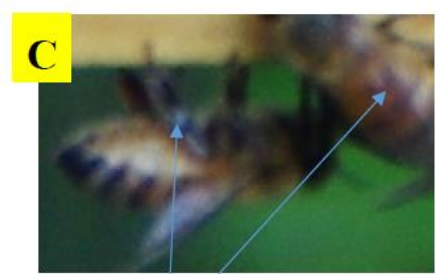

Mites
Traces of mites

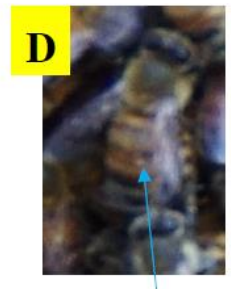

Traces of falling
Traces of mites

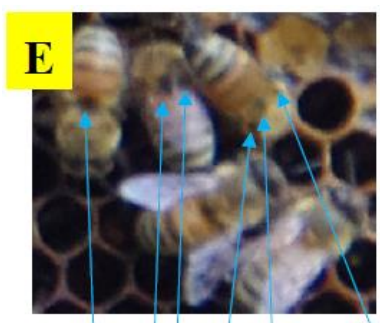

Traces of falling No wing
out

\section{Traces of mites}

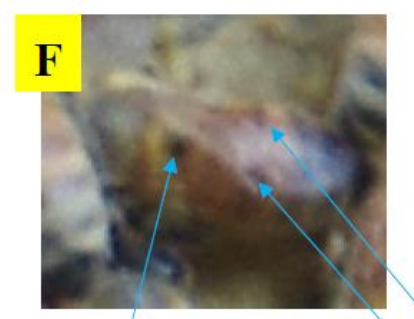

Trace of falling Traces bitten by out mites

Traces of mites

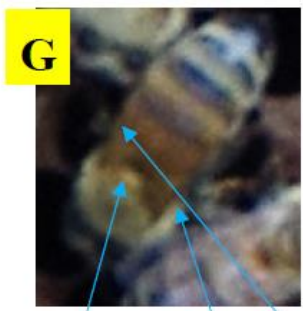

falling out

Figure 1. Images of mite-damaged bees. Several representative examples of mages of adult bees that appears to have been damaged by Varroa mite is shown. Each image is an example of the mite-damaged bee as follows. A: There is a mite on the back of an adult bee (worker bee) whose wing is removed. B: There is a mite on the head of a drone. C: There are mites on the bee's leg and back. D: There is a trace that a mite fell out on the bee's back. $\mathrm{E}$ : There are traces that mites fell out on the bee's back and the bee has no wing. F: There are traces that a mite fell out and it seems to have been bitten by mites. G: There is a trace that a mite fell out and the bee has no wings.

It is presumed that the impacts of Varroa mites on a bee colony appear directly in the adult bees with the damage caused by the mites. In this paper, we aim to measure the total number of bees damaged by mites, not the total number of mites in the bee colony. To count the number of mitedamaged bees as accurately as possible, the images and software used to count the number of adult bees are used again. Using this counting technique of the number of adult bees, it is relatively easy to count Varroa mites on an adult bee. On the other hand, it is very difficult to count Varroa mites that causes damage to a brood in a comb cell. If any damage is received from Varroa mites during the brood stage, it is thought that there is a trace of the damage even if the brood becomes an adult bee. An adult bee with traces of its brood stage is considered a mite-damaged bee. By the way, it is also conceivable that the mite of the adult bee with the mite drop out of the adult bee on the way. In this case, it has been confirmed that traces remain in the adult bee. Therefore, an adult bee with traces of mite falling-off are also regarded as a mite-damaged bee. 
For the determination of such traces, based on the information obtained by expanding the image, the criteria was created Supplementary Method S3). It should be noted that the image examples certified as mite- damage bees shown in Figure 1. According to this criterion, from the photographic image taken for the adult number measurement, it is possible to evaluate the situation of the Varroamite damage of almost the total number of adult bees in the bee colony. Therefore, the total number of both adult bees with Varroa mites and ones with traces of the Varro-mite damage, using the software used to measure the number of adult bees, manually, while enlarging the adult bee number measurement image, is determined. The measurement of the number of mite-damaged bees was a very difficult task and took a lot of time (about 6 months). Incidentally, this measurement, in order to eliminate the error between the operators, carried out only by one person.

\section{Results}

\subsection{The Period, Site and Purpose of the Long-Term Field Experiment}

So far, long-term field experiments have been conducted four times at an apiary owned by the author in Shika-machi, Hakui-gun, Ishikawa Prefecture, Japan, and once in Maui Island. These experimental conditions and the purpose of the experiment are described in Supplementary Table S1. The main points of these five experiments and this experiment are as follows: (1) 2011 experiment (Shika)-“Impacts of neonicotinoid pesticides on bee colonies (related to CCD)"; (2) 2011/2012 experiment (Shika)-“ Impacts of pesticide intake pathways (SS, PP) on bee colonies"; (3) 2012/2013 experiment-"Differences in the impacts of neonicotinoid pesticides on bee colonies between organophosphorus pesticides"; (4) 2013/2014 experiment-"Impacts of low concentrations of neonicotinoid and organophosphorus pesticides on bee colonies"; (5) 2013/2014 experiment- "Impacts of pesticides on bee colonies in areas without both mites and four seasons"; (6) 2018 experiment-" Reproduction experiment of the impact of PP with DF on bee colonies (one of 2011/2012 experimental results)" (this work).

\subsection{Observation Results in the Field Experiment}

Seasonal changes in the size (the numbers of adult bees and capped brood) and the miteprevalence on adult bees were investigated in bee colonies damaged by Varroa mites through a longterm field experiment of 180 days, which was conducted as below:

Three colonies of control (pesticide-free) (CR-1, CR-2, CR-3) and three dinotefuran-exposed colonies with a PP containing 0.4 ppm DF (DF-1, DF-2, DF-3) were placed from west to east every 80 $\mathrm{cm}$, with the front of the hive-box facing south (Supplementary Figure S4). On June 19, 2018, into all 8 colonies were administered pesticide-free PP $300 \mathrm{~g}$ and pesticide-free SS $800 \mathrm{~g}$, and the experiment was started. Incidentally, the SS of pesticide-free over the entire period of the experiment, was administered to all colonies. After that, the state of each hive-box was carefully observed, and six bee colonies which seemed to be almost the same activity were selected. Using the six bee colonies, the pesticide administration experiment was started from July, 2018.

From mid-August in 2018, all bee colonies began to be attacked by Japanese giant hornets and their attacks continued until early December in 2018. From the beginning of September to the end of October, their attacks were particularly intense. In order to prevent the attack of the Japanese giant hornet, the hornet capture was attached to the front of each hive-box in mid-August. At the beginning of October, the presence of Varroa mites in a few bee colonies were visually confirmed, because of the change in experimental conditions, the acaricide was not administered into the bee colony. In midNovember, all the hive-boxes were covered with a $5 \mathrm{~cm}$ in thick foamed-polystyrene plate to protect the cold (preparation for overwintering). The weather at the experiment (measurement) date and the start time and the end time are summarized in Supplementary Table S2. As can be seen from the experiment start time, the experiment (measurement) is started as early as possible, shortly after dawn before the outside bees go out to the foraging.

The situation at the time of experiments is summarized in Supplementary Table S3 (control colonies) and Supplementary Table S4 (DF-exposed colony). These tables reveal the followings: The 
queen bee in the DF-exposed colony is gone on the way, while the queen bee exists until the time of the extinction of the control colony: There was little damage due to wax-moth larvae in all colonies. All the colonies was expected to be included in overwintering, but with the exception of one colony (CR-1) of controls (which became extinct on December 16): all the remaining colonies became extinct before overwintering. That is, Df-3 became extinct early on 23 October, and CR-2, CR-3, DF-1 and DF2 became extinct on 2 December, just after the start of overwintering, and the slowest CR-1 on December 16. These extinctions are presumed to be caused by the spread of mites in addition to the attacks on Japanese giant hornets. The bee colony that appeared to be high activity at the beginning of the experiment, after the attack of the Japanese giant hornet, rapidly declined, all bee colonies became extinct around the start of overwintering.

\subsection{The Number of Adult Bees}

The field experiment, which started on June 19 and continued observation about every two weeks, was completed on December 16, about six months later (180 days). Based on the photograph which continued to be taken every observation day, the number of adult bees, the number of capped brood, and the number of bees damaged by mites were determined. The number of adult bees and the number of capped brood obtained in this way were displayed together in Table 1. Further, the number of adult bees in the table is shown in Figure 2. Note that the number of measurements of mite-damaged bees will be shown in "Discussion".

Table 1. Numbers of adult bees and capped brood. $k$ is the measurement number, $\Delta t k$ is an interval between two successive measurement days [day], $t_{k}$ is the elapsed days from the start of experiment (June 19, 2018). $a\left(t_{k}\right)$ and $b\left(t_{k}\right)$ are the numbers of adult bees and capped brood which were measured at a measurement day, respectively. CR-1, CR-2 and CR-3 are the control colonies, respectively. DF-1, DF-2 and DF-3 are the dinotefuran (DF) exposed colonies where dinotefuran was administered via pollen paste under the same experimental conditions.

\begin{tabular}{|c|c|c|c|c|c|c|c|c|c|c|c|c|c|c|c|c|}
\hline \multirow{2}{*}{ Date } & \multirow{2}{*}{$\boldsymbol{k}$} & \multirow{2}{*}{$\begin{array}{l}\Delta t_{k} \\
\text { [day] }\end{array}$} & \multirow{2}{*}{$\begin{array}{c}t_{k} \\
\text { [day] }\end{array}$} & \multicolumn{2}{|c|}{ CR-1 } & \multicolumn{2}{|c|}{ CR-2 } & \multicolumn{2}{|c|}{ CR-3 } & \multicolumn{2}{|c|}{ DF-1 } & \multicolumn{2}{|c|}{ DF-2 } & \multicolumn{2}{|c|}{ DF-3 } & \multirow{2}{*}{ Remarks } \\
\hline & & & & $a\left(t_{k}\right)$ & $b\left(t_{k}\right)$ & $a\left(t_{k}\right)$ & $b\left(t_{k}\right)$ & $a\left(t_{k}\right)$ & $b\left(t_{k}\right)$ & $a\left(t_{k}\right)$ & $b\left(t_{k}\right)$ & $a\left(t_{k}\right)$ & $b\left(t_{k}\right)$ & $a\left(t_{k}\right)$ & $b\left(t_{k}\right)$ & \\
\hline 19-Jun-18 & 1 & 0 & 0 & 8613 & 5341 & 8343 & 3065 & 6987 & 6861 & 9010 & 5891 & 9067 & 3241 & 7079 & 7726 & Start of Experiment \\
\hline 1-Jul-18 & 2 & 12 & 12 & 10507 & 11056 & 8439 & 9401 & 9830 & 8621 & 10188 & 9341 & 8926 & 12549 & 10071 & 5374 & Start of DF adminstration \\
\hline 16-Jul-18 & 3 & 15 & 27 & 13064 & 10657 & 12402 & 7447 & 12016 & 8060 & 12070 & 8360 & 13726 & 8755 & 10491 & 8032 & \\
\hline 28-Jul-18 & 4 & 12 & 39 & 12439 & 5688 & 11658 & 7640 & 10037 & 7006 & 11239 & 5443 & 11252 & 5769 & 10301 & 9052 & \\
\hline 12-Aug-18 & 5 & 15 & 54 & 6977 & 3817 & 9812 & 4619 & 6965 & 4078 & 8437 & 2777 & 8588 & 4030 & 9213 & 4840 & \\
\hline 28-Aug-18 & 6 & 16 & 70 & 6284 & 4125 & 9902 & 6629 & 6583 & 5277 & 7609 & 466 & 7558 & 5690 & 5662 & 4504 & \\
\hline 11-Sep-18 & 7 & 14 & 84 & 7369 & 4755 & 8589 & 5050 & 8081 & 6262 & 4716 & 395 & 8742 & 5928 & 4204 & 2978 & Attacks by giant hornets \\
\hline 23-Sep-18 & 8 & 12 & 96 & 6427 & 4201 & 9102 & 5636 & 6891 & \begin{tabular}{|l|}
6487 \\
\end{tabular} & 2370 & 200 & 8046 & 6559 & 1158 & 1266 & Attacks by giant hornets \\
\hline 6-Oct-18 & 9 & 13 & 109 & 3680 & 1490 & 8593 & 5982 & 6150 & 5015 & 964 & 105 & 7599 & 6091 & 41 & 1228 & Attacks by giant hornets \\
\hline 23-Oct-18 & 10 & 17 & 126 & 1187 & 658 & 6395 & 4200 & 3461 & 2773 & 309 & 70 & 4366 & 3113 & $\mathbf{0}$ & 1234 & Attacks by giant hornets \\
\hline 4-Nov-18 & 11 & 12 & 138 & 596 & 440 & 3373 & 1747 & 1332 & 1043 & 204 & 43 & 1957 & 1646 & & & Attacks by giant hornets \\
\hline 18-Nov-18 & 12 & 14 & 152 & 207 & 411 & 383 & 913 & 254 & 607 & 112 & 39 & 191 & 1147 & & & \\
\hline 2-Dec-18 & 13 & 14 & 166 & 56 & 460 & o & 989 & 0 & 691 & 0 & 72 & $\mathbf{0}$ & 1291 & & & \\
\hline 16-Dec-18 & 14 & 14 & 180 & 0 & 463 & & & & & & & & & & & \\
\hline
\end{tabular}

The queen bee of the control colony existed in all colonies until the extinction of the bee colony, but the queen bee of the DF-exposed colony disappeared before the extinction of the bee colony (DF1, DF-3), or died (DF-2). The difference in the presence or absence of a queen bee between the control colony and the DF exposed colony is probably due to the DF-ingestion of DF- exposed colony via PP containing DF. That is, since queen bees and brood mainly consume pollen (PP), which is a source of protein, and do not consume much honey (SS), which is the source of energy, it is estimated that the PP containing DF might be the result of the queen bee's active ingest. In a bee colony without a queen bee (DF-1, DF-3), the number of bees cannot increase like the control colony at a time when it increases in autumn. Around the start of the experiment, all colonies had active bees, and it was thought that all colonies might overwinter, but far from the success of the overwintering, all the colonies became extinct on December 16, before or shortly after the overwintering. 
As can be seen from Figure 2, after the start of the experiment in mid-June (June 19), the number of adult bees in all bee colonies except DF-3 increased and turned to decline after peaking in midJuly. This decrease is a common phenomenon in summer when there are few flowers in Japan. After that, the number of adult bees decreased in the second half of August, and it began to increase in September (these changes in number are often seen in Japan), but in the second half of September, the number declined sharply, and by the middle of December, all the colonies had become extinct. The following is a possible cause for this: The hornet catcher that had been installed on each hive-box was removed because of the typhoon that hit in early September. Immediately after the typhoon, there were attacks by Japanese giant hornets, so all the colonies suffered a lot of damage. After this, again, it was re-installed a hornet catcher at each hive-box, but continued to suffer damage from the Japanese giant hornet.

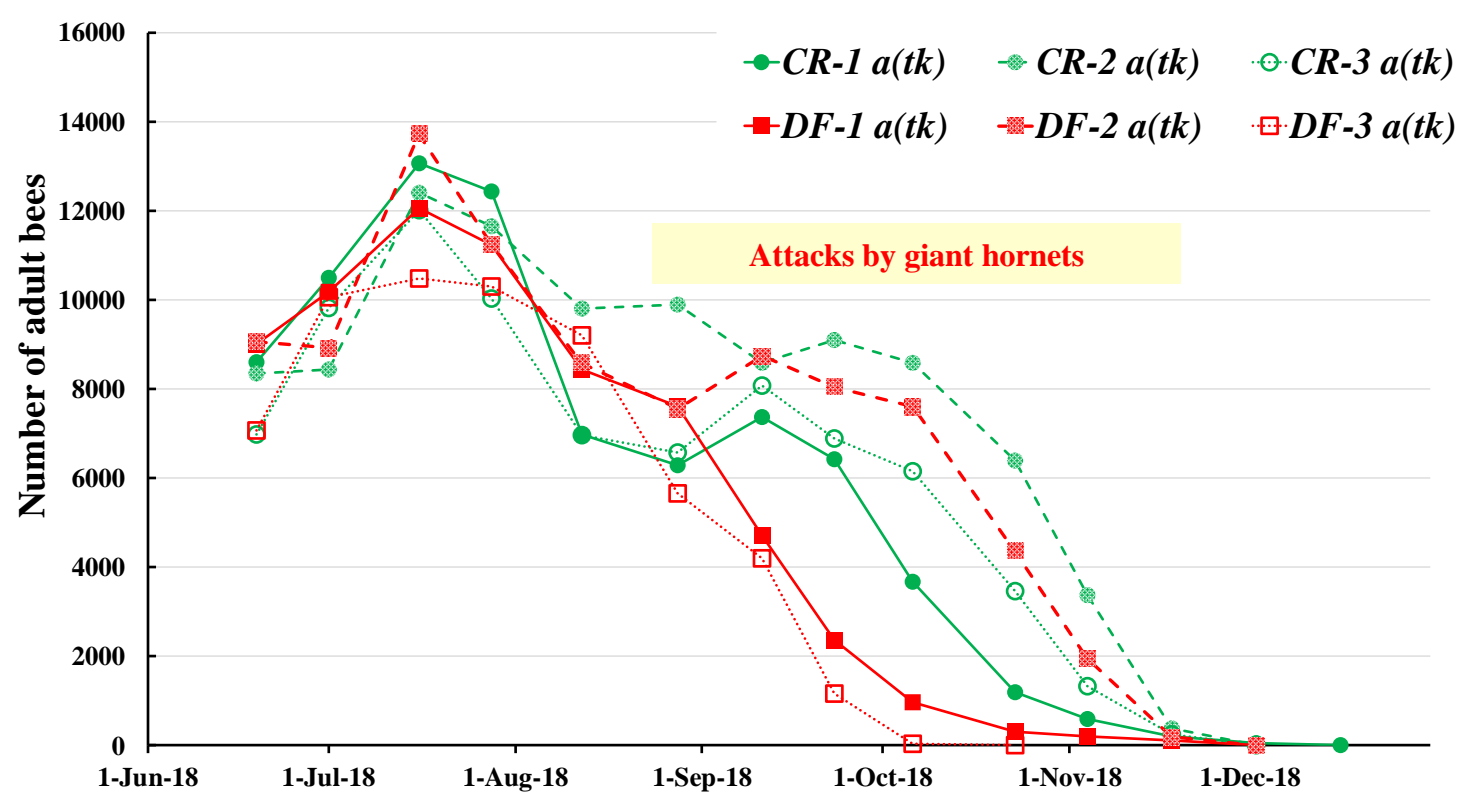

Figure 2. Numbers of adult bees. $a\left(t_{k}\right)$ is the number of adult bees that measured at the $k^{\text {th }}$ measurement day (after $t_{k}$ days elapsed from the start of experiment).

It was in early October that the presence of Varroa mites in the hive-box was visually confirmed, and it was in the middle of November that the damage due to the mites was confirmed (Supplementary Table S5). Later, while expanding the photo image taken, we examined it in detail, and found that all colonies had been mite-damaged bees from the start of the experiment. In previous experiments, there was no damage caused by ticks, so there is no denying that there was a lack of attention. It is thought that the extinction of even the control colony is that the bee colony which had been attacked by the mite became weak colony rapidly because of the attack of the Japanese giant hornet further. From the middle of September until the beginning of December when the colony become extinct, CR-2, CR-3 and DF-2, although there is a difference in the number of adult bees, show a similar change in the number of adult bees. CR-1 survived, until December 16, longer than other bees, even though the number of adult bees since mid-September was small. DF-1 and DF-3 have a much smaller number of bees in late August than other bee colonies, and there is no peak of the adult bee number in the middle of September seen in other bee colonies, and then they are decreasing. We'll discuss these results later.

\subsection{The Number of Capped Brood}

The measured value of the number of capped brood described in Table 1 is illustrated in Figure 3. From this figure, it can be seen that the number of capped brood of DF-3 is depressed in July.1-4. This is probably due to the fact that a new queen bee, sister relationship with the original, was placed in DF- 3 on July 1 when the original queen bee could not be found, and that bee eggs could not be laid 
during the periods of the queen bee absence and several days after new queen-bee placement. The numbers of capped brood in other colonies peak at the beginning of July, earlier than the numbers of adult bees peaking mid-July. This seems to reflect a time lag due to the life cycle of the honeybee. The reason why bee spawning is less in August is due to the small number of flowers that produce honey. This is a general trend. In September, the heat softens and flowers begin to bloom, so it is thought that the number of eggs laid increases. The rapid decrease in the number of eggs laid (the number of capped brood) in October is different from the usual situation in which the number of eggs laid begins to decrease around November. This is thought to be due to the attack of the Japanese giant hornet and the spread of mites to be described later.

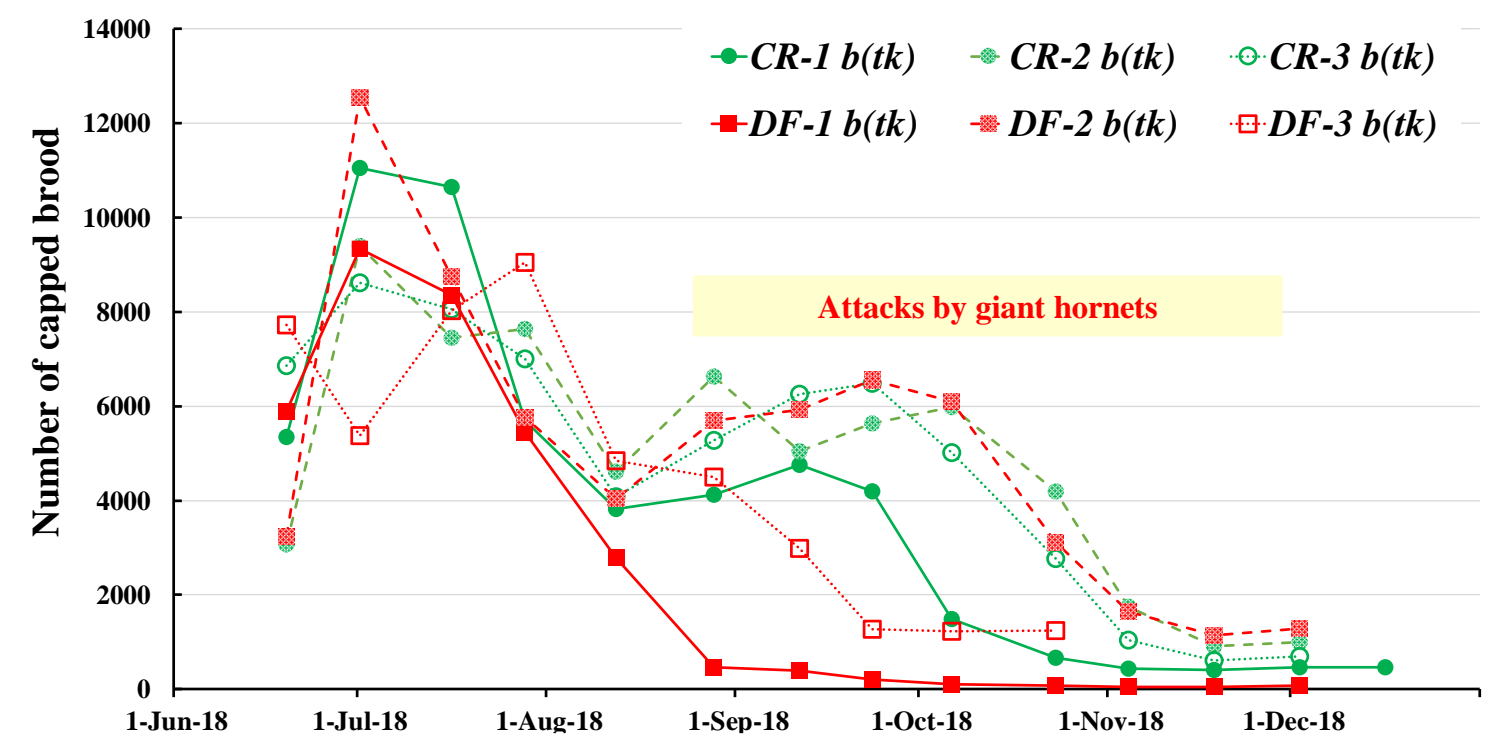

Figure 3. Numbers of capped brood. $b\left(t_{k}\right)$ is the number of capped brood that measured at the $k^{\text {th }}$ measurement day (after $t_{k}$ days elapsed from the start of experiment).

Here, about the individual bee colony, we will look at a little more detail. DF-1's increase in the number of capped brood at the start of the experiment (June 19) is at the same level as other bee colonies, but there is no increase in the number of capped brood from mid-August to early October. This may be due to the fact that the queen bee suffers from pesticides (DF) and mites, reducing the number of eggs laid, and also because the growth of larvae is poor (confirmed the absence of the queen bee on October 6). That the number of capped brood (eggs laid) from the beginning of September has decreased dramatically seems to be due to that the oviposition activity had decreased sharply from nearly a month before the queen bee disappeared. It should be noted that the egg become a capped brood about nine days after laying eggs. CR-2, DF-2 and CR-3 also showed substantially similar changes in the number of capped brood, peaking from mid-September to early October, after which the decreased bee colony became extinct (December 2). This tendency is very similar to the change in the number of adult bees. The number of capped brood increased from midJune to mid-July in DF-3, but the increase was less than that of other bee colonies. However, the number of capped brood of DF-3 is similar to other bee colonies in that it peaks in mid-July. However, the peak of the number of capped brood at the beginning of autumn, which is a normal decrease in the general bee colony, is not observed, and the number of capped brood from the beginning of autumn to winter decreases in the same way as DF-1. This trend is very similar to the DF-1, which lost the queen bee on the same day in early October (October 6), but has become extinct earlier than DF-1. It can be inferred that the reason for the earlier extinction of DF-3 than DF-1 was that the number of laid eggs (equivalent to the number of capped brood) after September was less than DF1. CR-1, on the other hand, lived longer after mid-September, even though the number of capped brood was smaller than CR-2, DF-2 and CR-3, as well as the number of adult bees. The cause of this will be discussed later. 


\subsection{The Number of Dead Bees}

In four field experiments we have conducted so far (see Supplementary Table S1), for example, even in the neonicotinoid-exposed colony, dead bees hardly occurred, it was almost the same as the control colony. In addition, the queen bee also existed until just before the extinction of the bee colony, and it exhibited a similar aspect to CCD, and after that the neonicotinoid-exposed colony became extinct. From the field experiment results, we estimated that neonicotinoids such as DF and clothianidin were the main causes of CCD. By the way, the number of dead bees of the neonicotinoidexposed colony, as long as it is not attacked by Japanese giant hornets, is about the same as the control colony. The number of dead bees is within 50 head at most within the measurement period ( 7 days or 14 days). However, if it was attacked by Japanese giant hornets, more than 1,000 dead bees were sometimes generated. Thus, since the influence on the experiment is large, in the queen bee activity period of the Japanese giant hornet in spring may hornet traps were set around the experimental site, with the cooperation of local people, to capture the queen bee. At the time of the attacks of Japanese giant hornets from the end of August, we installed a hornet catcher on the hive-box and tried to reduce the damage due to the hornet even a little. In this experiment (2018 experiment), the same measures against Japanese giant hornets as before were carried out. In mid-August, a hornet catcher was attached to each hive-box, but the hornet catcher was blown off by a typhoon at the beginning of September. Immediately after that, because it was attacked by Japanese giant hornets, major damage caused by the giant hornet occurred in the bee colony.

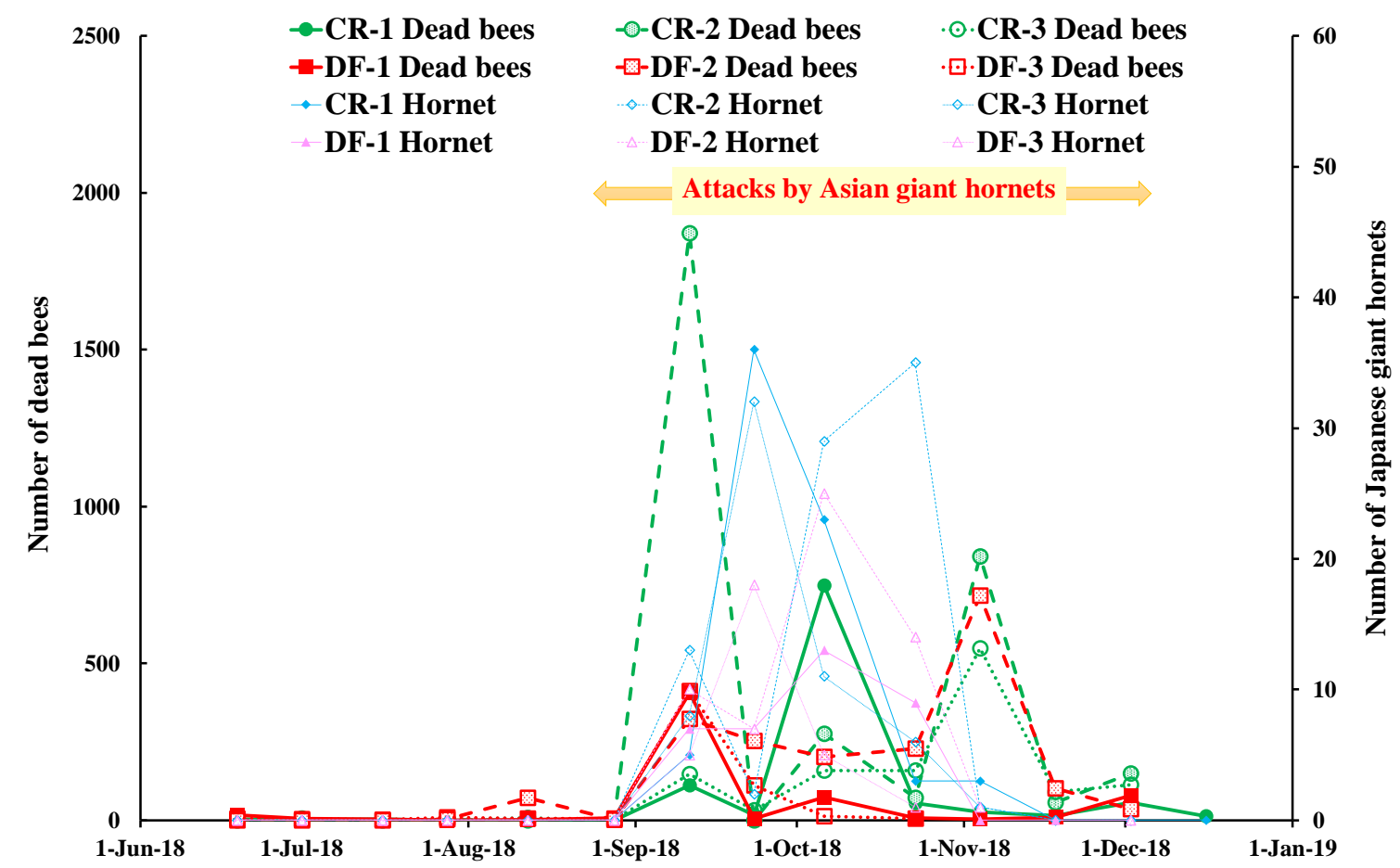

Figure 4. Number of dead bees. In this figure, the numbers of dead bees and Japanese giant hornets having attacked the bee colony between two consecutive measurement days are plotted.

Supplementary Table S3 shows the number of dead bees and the number of dying and dead Japanese giant hornets in each bee colony, where the number of dead bees includes the numbers of dead bees in the large tray installed under the hive-box and in the hive-box, and the number of dying and dead Japanese giant hornets include the numbers of giant hornets in the large tray, in the hornet catcher and in the hive-box. Each number in Supplementary Table S3 is the total number occurred between two consecutive measurement days. These are plotted in Figure 4. As can be seen from Figure 4, from the start of the experiment until the end of August, without distinction between the control colony and the pesticide (neonicotinoid) exposed colony, the number of dead bees is less than 20 head. However, the number of dead bees is increasing rapidly in September. This sharp increase 
may be due to attacks on Japanese giant hornets that begin in early September and continue until early December. The attack caused a great deal of damage to the bee colony and seemed to have affected the survival of the bee colony. It should be noted that the number of Japanese giant hornets is only a small part of the number of attacks, many Japanese giant hornets without being captured by the catcher or killed by bees, they seems to have returned to the nest.

\subsection{Measurement Results of the Number of Adult Bees Damaged by Varroa Mites (Mite-Damaged Bees)}

The presence of Varroa Mites was noticed in early October, but it was in mid-November when we felt convinced that the bee colony was being damaged by Varroa mites. Therefore, using the photo image taken, we decided to investigate the situation of the damage of the mite of all bees colony from the start of the experiment. As the most common method of quantifying the damage due to Varroa mites, a method of evaluating by the number of mites in the bee colony is considered. However, since it is impossible to count the total number of mites in each bee colony by enlarging the photo image (also mites exist in a capped brood cell), we decided to enlarge the photo image to count the number of bees with mites attached to them and the number of bees with traces of mites (see Figure 1 as examples of adult bees damaged by mites). Table 2 shows the number of adult bees damaged by Varroa mites (mite-damaged bees) and the total number of adult bees (including the number of mitedamaged bees) and the prevalence of adult bees due to mites (mite-prevalence) that is expressed by the ratio (percentage) of the number of mite-damaged bees to the total number of bees at each measurement day. The mite-damaged bees and the mite-prevalence are shown in Figure 5. In this experiment, since the number of adult bees is zero at the time of the bee colony extinction and it is not possible to determine the mite-presence, the mite-presence at the time of the colony extinction, judging from the mite-presence just before the colony extinction is assumed to be one.

The followings can be seen from Figure 5:

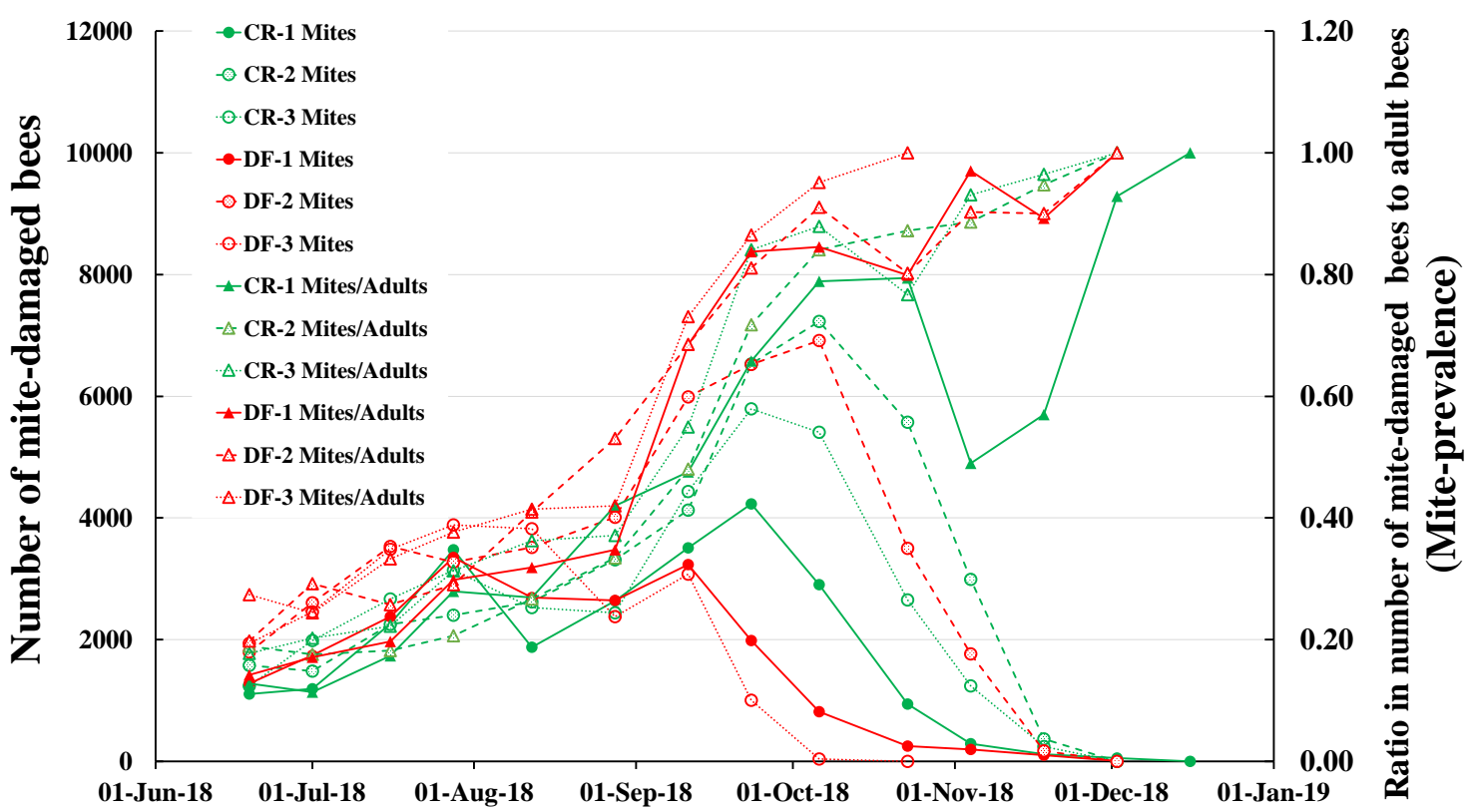

Figure 5. Number of mite-damaged bees and the mite-prevalence. The left vertical axis of the figure shows the number of mite-damaged bees at a measurement day, and the right vertical axis shows the mite-prevalence that is the ratio of the number of mite-damaged bees to the total number of adult bees (mite-prevalence) at a measurement day. "CR-1 Mite" and "CR-1 Mites/Adults" denote the number of mite-damaged bees and the mite-prevalence in the CR-1 colony, respectively. The other keys also denote them in each colony.

(1) The number of mite-damaged bees will begin to increase from the end of August, but it will begin to decline from the end of September to the beginning of October. This period of decrease in mite-damaged bees coincides with the time of decrease in the number of bees and the number of capped brood. Incidentally, the mite-prevalence is rapidly increased at the end of August, it continues 
to increase even if the mite-damaged bees is reduced, and the mite-prevalence approaches $100 \%$ before the colony extinction. The time of increases in the number of mite-damaged bees and the miteprevalence at the end of August coincides with the start of the attack of Japanese giant hornets. These increases seem to have been due to the weakening of the bee colony by the attack of Japanese giant hornets. The mite-prevalence continues to increase even if the number of mite-damaged bees turns to a decrease, because the rate of decrease in the total number of adult bees is higher than the rate of decrease in the number of mite-damaged bees.

(2) Roughly speaking, the mite-prevalence is substantially the same regardless of the bee colony. However, we don't know why, but CR-1 has seen a sharp decrease in mite-prevalence in early November. It can be estimated that CR-1 survived longer than other bees, due to this.

(3) The number of mite-damage bees in the bee colony does not change since the beginning of October, with CR-2 $>$ DF-2 $>$ CR-3 $>$ CR-1 $>$ DF- $1>$ DF-3, this order is the same as the order of the number of capped brood at this time. This can be understood from the increase in mites by parasitic on larvae in the bee colony.

Table 2. Numbers of damaged bees by Varroa mites \& adult bees and the ratio of number of the mite-damaged bees to number of adult bees at a measurement day in the 2018 experiment. "Mites", "Adults" and "M/A" denote the number of mite-damaged bees, the number of adult bees and the mite-prevalence which is the ratio in number of mite-damaged bees to adult bees, respectively.

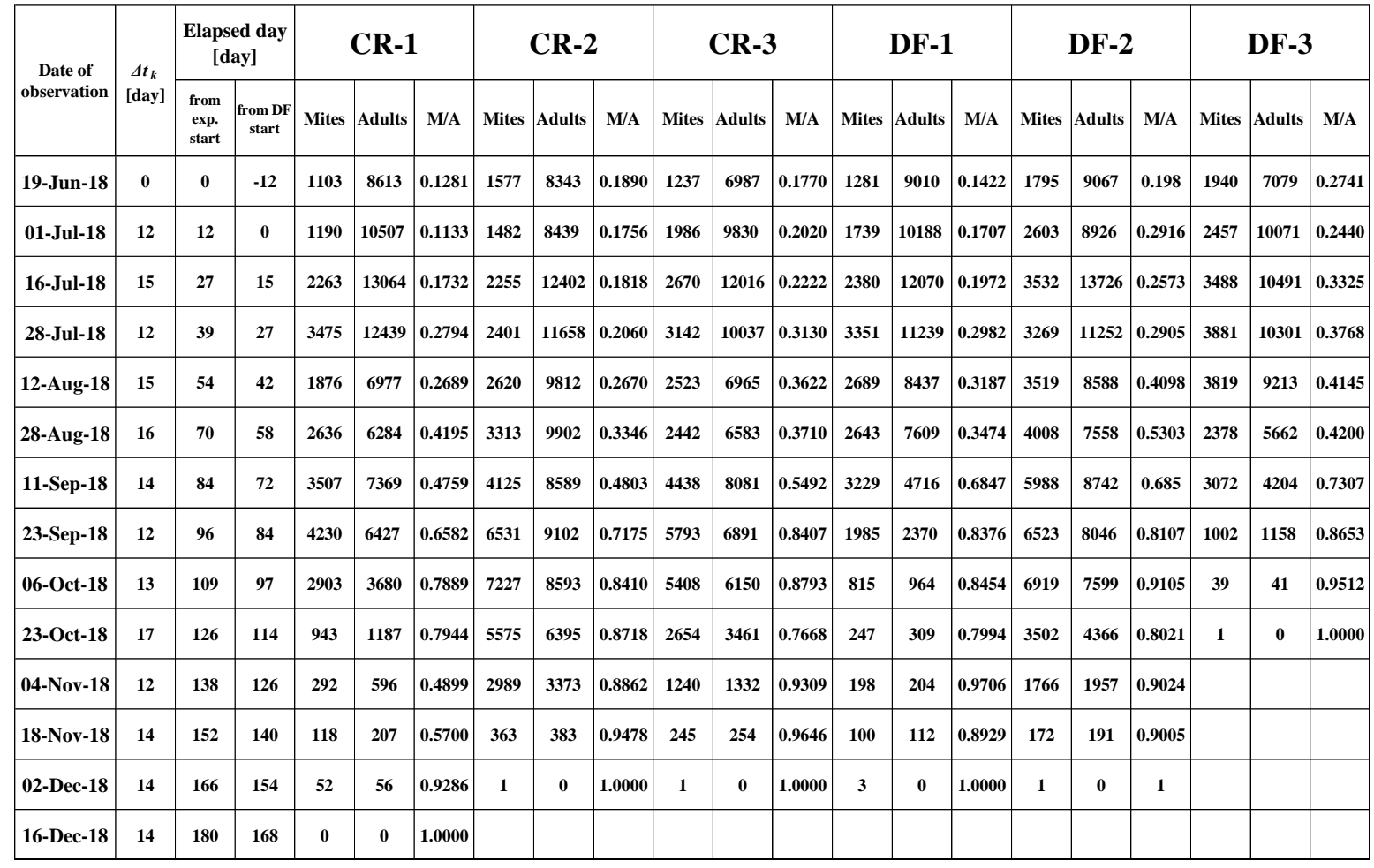

\subsection{The Inside and Outside Temperatures of Hive-Box}

To know the environmental conditions of the hive-box, the temperature and humidity data logger "EasyLog/El-USB-2" made by Lascar Electronics Inc. (see https://www.lascarelectronics.com/) was used to measure and record the temperature inside and outside the hive-box every hour. It is better to measure the temperature of all hive-boxes, but due to cost, the data logger was placed inside CR-1, CR-3, DF-1, DF-3 (farthest from the entrance at the bottom of the hive-box) and under the DF2 hive-box (in the tray) to achieve the outside temperature near the hive-box. In the data obtained from the data logger, CR-1 (TCR-1), DF-1 (TDF-1) and outside ambient temperature (Ta) were plotted in Figure 6. It can be seen from Figure 6 that: The variation width of the temperature (TCR-1, TDF-1) in the hive- box is less than the variation width of the ambient temperature (Ta). The temperature in the hive-box is adjusted with about $30^{\circ} \mathrm{C}$ of the ambient temperature as the boundary. If the ambient 
temperature (Ta) is lower than $30{ }^{\circ} \mathrm{C}$, the temperature in the hive-box is higher than the ambient temperature (Ta), if the ambient temperature (Ta) is higher than $30{ }^{\circ} \mathrm{C}$, the temperature in the hivebox is lower than the ambient temperature (Ta). Further, the temperature variation width of the DFexposed colony (DF-1) is greater than that of the control colony (CR-1).

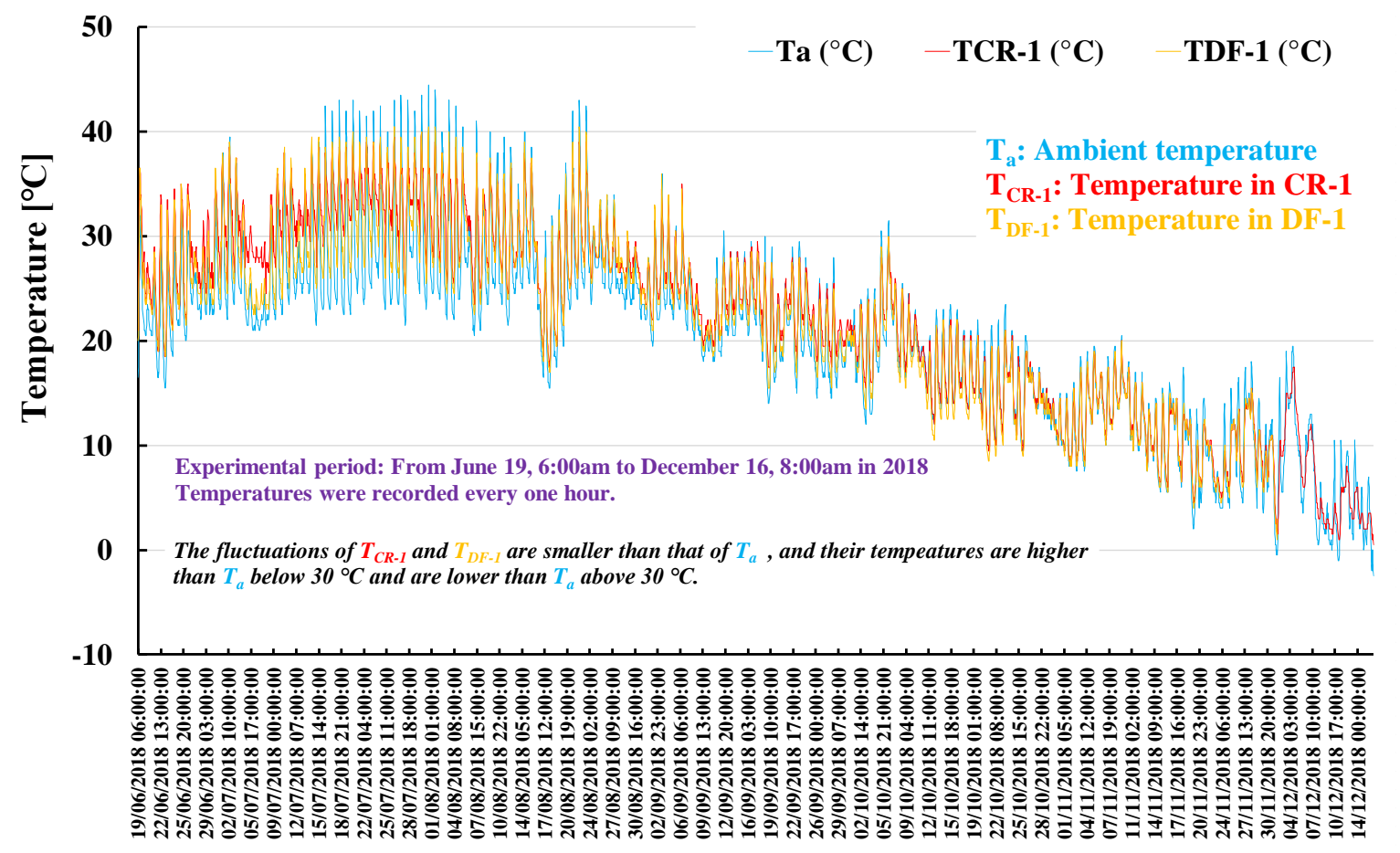

Figure 6. Temperature of ambient, CR-1 \& DF-1. Ta, TCR-1 and TDF-1 denote the temperature on the large tray under the DF-2 hive-box (ambient temperature), the temperature of the bottom inside the CR-1 hive-box and the temperature of the bottom inside the DF-1 hive-box, respectively. Temperatures were recorded every hour.

\subsection{Intakes of SS, PP and DF}

Now consider the intakes (consumptions) of SS $\left(S S_{k}\right), \mathrm{PP}\left(P P_{k}\right)$ and $\mathrm{DF}\left(D F_{k}\right)$ in the honeybee colony between the $(k-1)^{\text {th }}$ and the $k^{\text {th }}$ measurement day, where the start of experiment is $k=0 . S S_{k}$ and $P P_{K}$ are obtained by each remaining amount measured at the $k^{\text {th }}$ measurement day. $D F_{k}$ can be calculated from $P P_{k}$ with DF, by considering the concentration of DF in PP (in this work, the concentration is $0.4 \mathrm{ppm})$. When the number of days between the $(k-1)^{\text {th }}$ measurement day and the $k^{\text {th }}$ is $\Delta t_{k}$, the total number of honeybees in that period is $T N H B_{k}$, the average intake of SS per bee for $\Delta t_{k}$ days $\left(A I S S B_{k}\right)$, the average intake of SS per bee for $\triangle t_{k}$ days $\left(A I P P B_{\mathrm{k}}\right)$ and the average intake of DF per bee for $\triangle t_{k}$ days $\left(A I D F B_{k}\right)$, can be obtained from $S S_{k} / T N H B_{k}, P P_{k} / T N H B_{k}$ and $D F_{k} / T N H B_{k}$, respectively. Similarly, the average intake of SS per bee per day $\left(A I S S B D_{k}\right)$, the average intake of SS per bee per day $\left(A I P P B D_{k}\right)$ and the average intake of DF per bee per day $\left(A I D F B D_{k}\right)$ can be given by $S S_{k} / T N H B_{k} / \Delta t_{k}, P P_{k} / T N H B_{k} / \Delta t_{k}$ and $D F_{k} / T N H B_{k} / \Delta t_{k}$, respectively. Here $T N H B_{k}$ can be given by the sum of both the number of adult bees measured at the $k^{\text {th }}$ measurement day and the number of new adult bees having eclosed from pupae for $\Delta t_{k}$ days. It should be noted that adult bees measured at the $k^{\text {th }}$ measurement (initial adult bees) may have already ingested before the $k^{\text {th }}$ measurement day. Therefore, two cases will be considered in this paper, neglecting the pre-intake of adult bees and considering the pre-intake.

\subsubsection{Intakes of SS, PP and DF when Neglecting the Pre-intake of Initial Adult Bees}

- Intake of SS when neglecting the pre-intake of adult bees

Pesticide-free SS of $800 \mathrm{~g}$ in all bee colony was fed every time on the measurement day, the consumption of SS was calculate from the remaining amount. The intake (consumption) of SS of each bee colony is shown in Table 3. In Table 3, the intake of SS per colony $\left(S S_{k}\right)$ is consumed in two 
consecutive measurement days $\left(\Delta t_{k}\right)[\mathrm{g}]$, the average intake of SS per bee (AISSBk) for $\Delta t_{k}$ days $[\mathrm{mg} / \mathrm{bee}]$ and the average intake of SS per bee per day $\left(A I S S B D_{k}\right)$ for $\Delta t_{k}$ days [mg/bee/day] are shown. In the last line of Table 3, the following grand totals are shown in the last line of Table 3: From the administration start of DF (July 1) until the extinction of bee colony, the grand total number of adult bees in each bee colony and the average intake (consumption) of SS per bee, the average intake of SS per bee per day. The intake of SS per bee per day in each measurement period [mg/bee/day] was described in Figure 7. Table 3 and Figure 7 can be seen as follows.

Table 3. Consumption of sugar syrup between two consecutive measurement days in each colony without consideration of sugar syrup already ingested by the initial honeybees. This table shows the calculated intake of sugar syrup (SS) between two consecutive measurement days without considering the amount of SS that adult bees measured at a measurement day (initial honeybees) have already ingested till then. $k=$ Measurement date number. $\Delta t_{k}=$ Period between two measurement date numbers of $k-1$ and $k$. CR-1, CR-2, CR-3 = Control (pesticide-free) colonies. DF-1, DF-2, DF-3 = Colonies (DF-exposed colonies) where dinotefuran is administered through pollen paste. $T N H B K=$ Total number of honeybees involved in the consumption (intake) of sugar syrup during the period from the measurement date number of $k-1$ to that of $k$. AISSB $k=$ Average intake of sugar syrup per bee between the measurement date numbers of $k-1$ and $k[\mathrm{mg} / \mathrm{bee}]$. $A I S S B D_{k}=$ Average intake of sugar syrup per bee per day [mg/bee/day]. From June 19 (start of experiment) to July 1 ( start of DF administration), 800g of sugar syrup (pesticide-free) and $300 \mathrm{~g}$ of pollen paste (pesticide-free) were fed to every colony, but the consumptions of sugar syrup and pollen paste were not recorded.

\begin{tabular}{|c|c|c|c|c|c|c|c|c|c|c|c|c|c|c|c|c|c|c|c|c|c|c|c|c|c|c|}
\hline \multirow{2}{*}{ Date } & \multirow{2}{*}{$\boldsymbol{k}$} & \multirow{2}{*}{$\begin{array}{l}\Delta t_{k} \\
\text { [day] }\end{array}$} & \multicolumn{4}{|c|}{ CR-1 } & \multicolumn{4}{|c|}{ CR-2 } & \multicolumn{4}{|c|}{ CR-3 } & \multicolumn{4}{|c|}{ DF-1 } & \multicolumn{4}{|c|}{ DF -2 } & \multicolumn{4}{|c|}{ DF-3 } \\
\hline & & & \begin{tabular}{|l|}
$\mathrm{TNHB}_{\mathrm{k}}$ \\
\end{tabular} & $\mathrm{ss}_{\mathbf{k}}[\mathrm{g}]$ & AISSB $_{\mathrm{k}}$ & \begin{tabular}{|l|l|} 
AISSBD $_{k}$ & \\
\end{tabular} & \begin{tabular}{|l|}
$\mathrm{TNHB}_{\mathrm{k}}$ \\
\end{tabular} & $\mathrm{ss}_{\mathrm{k}}[\mathrm{g}]$ & AISSB $_{\mathrm{x}_{\mathrm{x}}}$ & \begin{tabular}{|l|} 
AISSBD $_{k}$ \\
\end{tabular} & $\mathrm{TNHB}_{\mathrm{k}}$ & $\mathrm{ss}_{\mathrm{L}}[\mathrm{gl}$ & \begin{tabular}{|l|l|} 
AISSB $_{\mathrm{k}}$ \\
\end{tabular} & \begin{tabular}{|l|l|} 
AISSBD $_{k}$ \\
\end{tabular} & TNHB $_{k}$ & $\mathrm{ss}_{\mathrm{k}}[\mathrm{g}]$ & \begin{tabular}{|l|} 
AISSB $_{\text {ki }}$ \\
\end{tabular} & \begin{tabular}{|l|l|} 
AISSBD $_{k}$ & \\
\end{tabular} & $\mathrm{TNHB}_{\mathrm{k}}$ & \begin{tabular}{|l|}
$\mathrm{ss}_{\mathrm{k}}[\mathrm{g}]$ \\
\end{tabular} & \begin{tabular}{|l|l|} 
AISSB $_{\mathrm{k}}$ & \\
\end{tabular} & \begin{tabular}{|l|l|} 
AISSBD $_{k}$ \\
\end{tabular} & $\mathrm{TNHB}_{k}$ & $\mathrm{ss}_{\mathrm{k}}[\mathrm{g}]$ & $\mathrm{AISSB}_{\mathrm{k}}$ & AIS \\
\hline 19-Jun-18 & 0 & 0 & & & & & & & & & & & & & & & & & & & & & & & & \\
\hline 1-Jul-18 & 1 & 12 & & 0 & 0.6 & 0.00 & 11408.0 & 0 & 0.00 & 0.00 & \begin{tabular}{|l|}
13848.0 \\
\end{tabular} & 0 & . & & 901.0 & 0 & & 0.00 & 12308.0 & 0 & 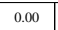 & 10 & 4805.0 & 0 & 00 & .00 \\
\hline & 3 & 12 & 21.0 & 800 & .73 & 2.81 & 19849.0 & 800 & & 3.36 & 20076.0 & 800 & 85 & 3.32 & 20430.0 & 800 & 39.16 & 3.26 & 22481.0 & 800 & 59 & 2.97 & 3.0 & 800 & 43.19 & 3.60 \\
\hline Aug-18 & 4 & 15 & 549.0 & 800 & .92 & 2.73 & 21208.0 & 800 & & 2.51 & 794.5 & 800 & 57 & 2.84 & 18042.7 & 800 & 44.34 & 2.96 & 18463.3 & 800 & .33 & 2.89 & \begin{tabular}{|l|}
21616.0 \\
\end{tabular} & 800 & 37.01 & 2.47 \\
\hline-18 & 5 & 16 & 66.3 & 80 & 30 & 4.14 & \begin{tabular}{|l|}
15970.7 \\
\end{tabular} & 800 & 50.09 & 3.13 & 402.3. & 800 & .50 & 4.03 & 12139.7 & 800 & 65.90 & 4.12 & 13961.3 & 800 & 7.30 & 3.58 & \begin{tabular}{|l|}
15666.3 \\
\end{tabular} & 800 & 51.07 & 3.19 \\
\hline $6-C$ & 8 & 13 & 10978.1 & 523 & 47.64 & 3.66 & 15207.7 & 800 & 52.60 & 4.05 & 13918.6 & 800 & 57.48 & 4.42 & 2586.7 & 800 & 309.27 & 23.79 & 15151.6 & 800 & 52.80 & 4.06 & 2529.5 & 303 & 19.79 & 9.21 \\
\hline 23-Oct-18 & 9 & 17 & \begin{tabular}{|l|l|}
6790.8 \\
\end{tabular} & 228.3 & 33.62 & 1.98 & 17067.5 & 800 & 46.87 & 2.76 & 13254.6 & 598.4 & 45.15 & 2.66 & 1112.8 & 800 & 718.91 & 42.29 & 16237.9 & 674 & 41.51 & 2.44 & 1780.7 & 465 & 61.13 & 15.36 \\
\hline 4-Nov-18 & 10 & 12 & \begin{tabular}{|l|}
1845.0 \\
\end{tabular} & 50.8 & 27.53 & 2.29 & 10595.0 & 452.1 & 42.67 & 3.56 & 6234.0 & 90 & 14.44 & 1.20 & 379.0 & 44.4 & 117.15 & 9.76 & \begin{tabular}{|l|}
7479.0 \\
\end{tabular} & 323.6 & 43.27 & 3.61 & & & & \\
\hline 18-Nov-18 & 11 & 14 & \begin{tabular}{|l|}
1109.3 \\
\end{tabular} & 11 & 9.92 & 0.71 & \begin{tabular}{|l|}
5411.2 \\
\end{tabular} & 121 & 22.36 & 1.60 & 2548.8 & 49 & 19.22 & 1.37 & 254.2 & 26.5 & 104.25 & 7.45 & \begin{tabular}{|l|l|}
3877.3 \\
\end{tabular} & 174 & 44.88 & 3.21 & & & & \\
\hline 2-Dec-18 & 12 & 14 & \begin{tabular}{|l|}
686.5 \\
\end{tabular} & 51 & \begin{tabular}{l|l|}
74.29 \\
\end{tabular} & 5.31 & \begin{tabular}{|l|}
1448.2 \\
\end{tabular} & 0 & 0.00 & 0.00 & \begin{tabular}{|l|}
962.2 \\
\end{tabular} & 12 & 12.47 & 0.89 & 157.5 & - & 25.40 & 1.81 & 1529.2 & 11 & 7.19 & 0.51 & & & & \\
\hline 16-Dec-18 & 13 & 14 & \begin{tabular}{|l|}
592.7 \\
\end{tabular} & 0 & 0.00 & 0.00 & & & & & & & & & & & & & & & & & & & & \\
\hline
\end{tabular}

(1) The $A I S S B D_{k}$ of the DF-exposed colony is not less than the $A I S S B D_{k}$ of the control (pesticidefree) colony, and rather more. This result suggests that the excitable action of neonicotinoid pesticides such as DF may have tried to ingest more SS.

(2) The intake of SS per bee per day between $\Delta t_{k}$ is about $4 \mathrm{mg} / \mathrm{bee} /$ day on average, in rare cases, it reaches 10 times (DF-1).

(3) The intake of SS per bee from the DF-administration start (July 1) to the colony extinction (Grand total in Table 3) [mg/bee] is: 80.33 for CR-1; 85.07 for CR-2; 77.35 for CR-3; 137.81 for DF-1; 79.51 for DF-2; 80.14 for DF-3. With the exception of DF-1 (ca. $138 \mathrm{mg} / \mathrm{bee}$ ), the DF-exposed colony, without distinction of the control colony, is almost $80 \mathrm{mg} / \mathrm{bee}$.

(4) The average intake of SS per bee per day (grand total) is $0.4782 \mathrm{mg} / \mathrm{bee} /$ day (CR-1); 0.5524 mg/bee/day(CR-2); 0.5023 mg/bee/day(CR-3); 0.8949 mg/bee/day (DF-1); 0.5163 mg/bee/day (DF-2); $0.7030 \mathrm{mg} / \mathrm{bee} /$ day (DF-3). The average daily SS intake per bee (overall average in the experimental period) in DF-exposed colony $(0.7047 \mathrm{mg} / \mathrm{bee} / \mathrm{day})$ is higher than the average intake of the control colony $(0.5110 \mathrm{mg} / \mathrm{bee} /$ day). From this fact, neonicotinoid pesticides (DF) may have an appetiteenhancing effect. Perhaps DF excites bees and boosts bee colony activity? Further, the average intake of DF per bee per day until the extinction of the DF-exposed colony has, also larger variation between colonies than that of the control colony. 


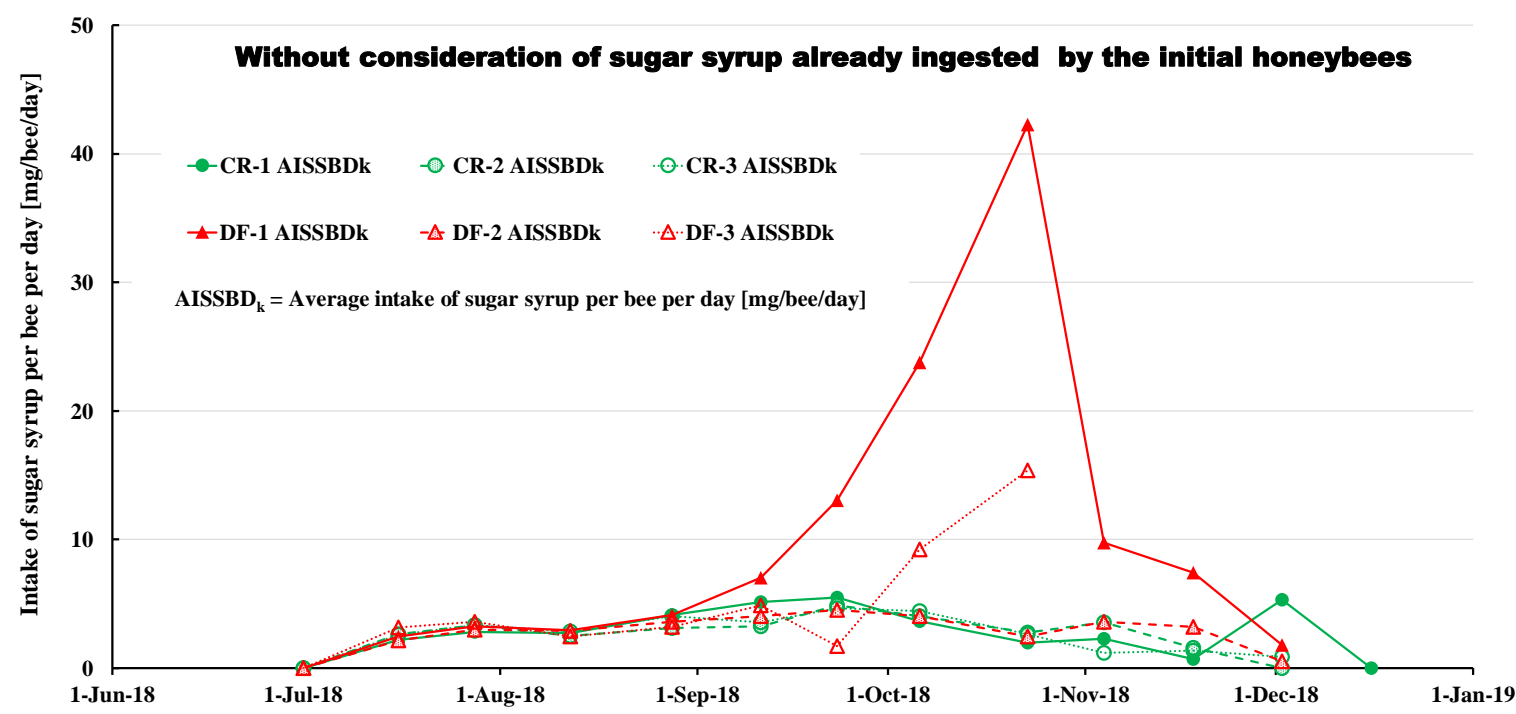

Figure 7. Average intake of sugar syrup per bee per days between two adjacent measurement dates in each colony without consideration of sugar syrup already ingested by the initial honeybees. This figure shows the calculated intake of sugar syrup (SS) per bee per day without considering the amount of SS that adult bees measured at a measurement day (initial honeybees) have already ingested till then.

- Intake of PP when Neglecting the Pre-Intake of Initial Adult Bees

The PP of 300g (mainly) or 500g in each bee colony was fed every time on the measurement day, the intake (consumption) of PP was calculated from the remaining amount. The intake of PP of each bee colony $\left(A I P P B_{k}\right)$ is shown in Table 4 . In Table 4, it described the same information as the SS. Similar to the SS, the average intake of PP per bee per day in each measurement interval $\left(A I P P B D_{k}\right)$ [mg /bee /day] is shown in Figure 8. From Figure 8 and Table 4, the followings can be seen that:

Table 4. Consumption of pollen paste between two consecutive measurement days in each colony without consideration of pollen paste already ingested by the initial honeybees. This table shows the calculated intake of pollen paste (PP) between two consecutive measurement days without considering the amount of PP that adult bees measured at a measurement day (initial honeybees) have already ingested till then. $A I P P B k=$ Average intake of pollen paste per bee between the measurement date numbers of $k-1$ and $k[\mathrm{mg} / \mathrm{bee}]$. AIPPBD $=$ Average intake of pollen paste per bee per day [mg/bee/day]. The other terms should be seen in the legends of Table 3 .

\begin{tabular}{|c|c|c|c|c|c|c|c|c|c|c|c|c|c|c|c|c|c|c|c|c|c|c|c|c|c|c|}
\hline \multirow{2}{*}{ Date } & \multirow{2}{*}{$\boldsymbol{k}$} & \multirow{2}{*}{$\begin{array}{r}\Delta t_{k} \\
\text { [day] }\end{array}$} & \multicolumn{4}{|c|}{ CR-1 } & \multicolumn{4}{|c|}{ CR-2 } & \multicolumn{4}{|c|}{ CR-3 } & \multicolumn{4}{|c|}{ DF-1 } & \multicolumn{4}{|c|}{ DF-2 } & \multicolumn{4}{|c|}{ DF-3 } \\
\hline & & & $\mathrm{TNHB}_{k}$ & \begin{tabular}{|l|}
$\mathrm{SS}_{\mathrm{k}}[\mathrm{g}]$ \\
\end{tabular} & $\mathrm{AIPPB}_{\mathrm{k}}$ & $A^{A I P P B D}{ }_{k}$ & $\mathrm{TNHB}_{\mathrm{k}}$ & $\mathrm{SS}_{\mathrm{k}}[\mathrm{g}]$ & $\mathrm{AIPPB}_{\mathrm{k}}$ & $\mathrm{AIPPBD}_{\mathrm{k}}$ & $\mathrm{TNHB}_{\mathrm{k}}$ & $\mathrm{SS}_{\mathrm{k}}[\mathrm{g}]$ & $\mathrm{AIPPB}_{\mathrm{k}}$ & $\mathrm{AIPPBD}_{k}$ & $\mathrm{TNHB}_{\mathrm{k}}$ & SS $5 S_{k}[\mathrm{~g}]$ & $\mathrm{AIPPB}_{\mathrm{k}}$ & $\mathrm{AIPPBD}_{\mathrm{k}}$ & $\mathrm{TNHB}_{\mathrm{k}}$ & $\mathrm{ss}_{\mathrm{k}}[\mathrm{g}]$ & $\mathrm{AIPPB}_{\mathrm{k}}$ & $A^{A I P P B D}{ }_{k}$ & $\mathrm{TNHB}_{\mathrm{k}}$ & \begin{tabular}{|l|}
$S_{\mathrm{k}}[\mathrm{g}]$ \\
\end{tabular} & $\mathrm{AIPPB}_{\mathrm{k}}$ & AIPP \\
\hline nn-18 & 0 & 0 & & & & & & & & & & & & & & & & & & & & & & & & \\
\hline 1-Jul-18 & 1 & 12 & 354.0 & 0 & 0.00 & 0.000 & \begin{tabular}{|l|l|}
1408.0 \\
\end{tabular} & 0 & 0.00 & 0.000 & \begin{tabular}{|l|}
13848.0 \\
\end{tabular} & 0 & 0.00 & 0.000 & \begin{tabular}{|l|}
14901.0 \\
\end{tabular} & 0 & 0.00 & 0.000 & \begin{tabular}{|l|}
12308.0 \\
\end{tabular} & 0 & 0.00 & 0.000 & \begin{tabular}{|l|}
14805.0 \\
\end{tabular} & 0 & 0.00 & 0.000 \\
\hline 28-Jul-18 & 3 & 12 & \begin{tabular}{|l|}
23721.0 \\
\end{tabular} & 300 & 12.65 & 1.054 & \begin{tabular}{|l|l|}
19849.0 \\
\end{tabular} & 300 & 15.11 & 1.260 & \begin{tabular}{|l|}
20076.0 \\
\end{tabular} & 300 & 14.94 & 1.245 & \begin{tabular}{|l|}
20430.0 \\
\end{tabular} & 300 & 14.68 & 0.000 & \begin{tabular}{|l|}
22481.0 \\
\end{tabular} & 300 & 13.34 & 1.112 & \begin{tabular}{|l|}
18523.0 \\
\end{tabular} & 300 & 16.20 & 1.350 \\
\hline 12-Aug-18 & 4 & 15 & \begin{tabular}{|l|}
19549.0 \\
\end{tabular} & 300 & 15.35 & 1.023 & 21208.0 & 300 & 14.15 & 0.943 & \begin{tabular}{|l|}
18794.5 \\
\end{tabular} & 300 & 15.96 & 1.064 & \begin{tabular}{|l|}
18042.7 \\
\end{tabular} & 300 & 16.63 & 0.915 & \begin{tabular}{|l|l|}
18463.3 \\
\end{tabular} & 300 & 16.25 & 1.083 & \begin{tabular}{|l|}
21616.0 \\
\end{tabular} & 300 & 13.88 & 0.925 \\
\hline 28-Aug-18 & 5 & 16 & \begin{tabular}{|l|}
12066.3 \\
\end{tabular} & 500 & 41.44 & 90 & \begin{tabular}{|l|l}
15970.7 \\
\end{tabular} & 500 & 31.31 & 1.957 & \begin{tabular}{|l|}
12402.3 \\
\end{tabular} & 500 & 40.32 & 2.520 & \begin{tabular}{|l|}
12139.7 \\
\end{tabular} & 500 & 41.19 & 2.574 & \begin{tabular}{|l|}
13961.3 \\
\end{tabular} & 500 & 35.81 & 2.238 & 15666.3 & \begin{tabular}{|l|}
351.3 \\
\end{tabular} & 22.42 & .401 \\
\hline 6-Oct-18 & 8 & 13 & 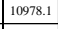 & \begin{tabular}{|l|} 
\\
\end{tabular} & 13.34 & 1.027 & 15207.7 & 300 & 19.73 & 1.51 & \begin{tabular}{|l|}
13918.6 \\
\end{tabular} & 264 & 18.97 & 1.459 & \begin{tabular}{|l|}
2586.7 \\
\end{tabular} & 18 & 6.96 & 0.535 & \begin{tabular}{|l|}
15151.6 \\
\end{tabular} & 255 & 16.83 & 1.295 & 2529.5 & 0 & 0.00 & 0.000 \\
\hline 23-Oct-18 & 9 & 17 & \begin{tabular}{|l|}
6790.8 \\
\end{tabular} & 33.4 & 4.92 & 0.289 & 17067.5 & 300 & 17.58 & 1.034 & \begin{tabular}{|l|}
13254.6 \\
\end{tabular} & 136.3 & 10.28 & 0.605 & \begin{tabular}{|l|}
1112.8 \\
\end{tabular} & 2.2 & 1.98 & 0.116 & \begin{tabular}{|l|}
16237.9 \\
\end{tabular} & \begin{tabular}{|l|}
215.7 \\
\end{tabular} & 13.28 & 0.781 & \begin{tabular}{|l|}
1780.7 \\
\end{tabular} & 0 & 0.00 & 0.000 \\
\hline 4-Nov-18 & 10 & 12 & \begin{tabular}{|l|}
1845.0 \\
\end{tabular} & 6.6 & 3.58 & 0.298 & \begin{tabular}{|l|l|l|}
10595.0 \\
\end{tabular} & 112.5 & 10.62 & 0.885 & \begin{tabular}{|l|}
6234.0 \\
\end{tabular} & 20.4 & 3.27 & 0.273 & \begin{tabular}{|l|}
379.0 \\
\end{tabular} & 0 & 0.00 & 0.000 & \begin{tabular}{|l|}
7479.0 \\
\end{tabular} & 30 & 4.01 & 0.334 & & & & \\
\hline 18-Nov-18 & 11 & 14 & \begin{tabular}{|l|}
1109.3 \\
\end{tabular} & 2 & 1.80 & 0.129 & 5411.2 & 6 & 1.11 & 0.079 & \begin{tabular}{|l|}
2548.8 \\
\end{tabular} & 8 & 3.14 & 0.224 & \begin{tabular}{|l|}
254.2 \\
\end{tabular} & 0 & 0.00 & 0.000 & \begin{tabular}{|l|} 
\\
\end{tabular} & 0 & 0.00 & 0.000 & & & & \\
\hline 2-Dec-18 & 12 & 14 & 686.5 & 0 & 0.00 & 0.000 & \begin{tabular}{|l|l|}
1448.2 \\
\end{tabular} & 0 & 0.00 & 0.000 & 962.2 & 0 & 0.00 & 0.000 & 157.5 & 0 & 0.00 & 0.000 & \begin{tabular}{|l|}
1529.2 \\
\end{tabular} & 0 & 0.00 & 0.000 & & & & \\
\hline 16-Dec-18 & 13 & 14 & 592.7 & 0 & 0.00 & 0.000 & & & & & & & & & & & & & & & & & & & & \\
\hline & & & $2^{2}$ & 2415.9 & 34.26 & 0.204 & 871.4 & 3118.5 & 38. & 0.247 & 1900.1 & 2789.1 & 33.98 & 0.221 & 98535.5 & \begin{tabular}{|l|}
7793.2 \\
\end{tabular} & 38.16 & 0.248 & 13307.2 & \begin{tabular}{|l|}
2653.9 \\
\end{tabular} & 31.11 & 0.202 & 59900.7 & 1440.3 & 24.04 & 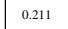 \\
\hline
\end{tabular}

(1) Average PP intake per bee between $\Delta t_{k}$ is about $3 \mathrm{mg} / \mathrm{bee} /$ day at most.

(2) The $A I P P B_{k}$ of the DF-exposed colony is less than the AIPPB $k$ of the control colony. Except DF-3, which became earliest extinct, however, the difference is small.

(3) Of course, the intake of PP is decreasing in the same trend as the number of capped brood decreases toward winter. By the way, the intake of SS is different from the change in intake of PP, not much related to the number of capped brood, is substantially constant, there is a tendency to decrease just before the colony extinction. 
(4) The amount of PP consumed by one bee from the start of DF administration start (July 1) to the colony extinction is as follows (see "Grand total" at the last line of Table 4): $34.26 \mathrm{mg} / \mathrm{bee}$ (CR-1); $38.04 \mathrm{mg} / \mathrm{bee}$ CR-2); $33.98 \mathrm{mg} / \mathrm{bee}$ (CR-3); $38.16 \mathrm{mg} / \mathrm{bee}$ (DF-1); $31.11 \mathrm{mg} / \mathrm{bee}$ (DF-2); $24.04 \mathrm{mg} / \mathrm{bee}$ (DF-3). Roughly speaking, DF-exposed colony, without distinction of the control colony, the average intake per bee from July 1 to the colony extinction is $25-35 \mathrm{mg} / \mathrm{bee}$. From this fact, it can be said that the bee does not avoid neonicotinoid pesticides such as DF and ingests PP equally as pesticide-free. This result is consistent with our previous results [4].

(5) The average amount of PP consumed in a day by one bee between July 1 and the colony extinction is as follows: $0.204 \mathrm{mg} / \mathrm{bee} /$ day (CR-1); $0.247 \mathrm{mg} / \mathrm{bee} /$ day (CR-2); $0.221 \mathrm{mg} / \mathrm{bee} /$ day (CR-3); $0.248 \mathrm{mg} / \mathrm{bee} /$ day (DF-1); $0.202 \mathrm{mg} / \mathrm{bee} /$ day (DF-2); $0.211 \mathrm{mg} / \mathrm{bee} /$ day (DF-3). Since there is little difference between the DF-exposed colony (ca. $0.220 \mathrm{mg} / \mathrm{bee} /$ day) and the control colony (ca. 0.224 $\mathrm{mg} /$ bee/day), neonicotinoid pesticides such as DF have no repellent effect, rather appetite enhancement effect is also implied as well as SS.

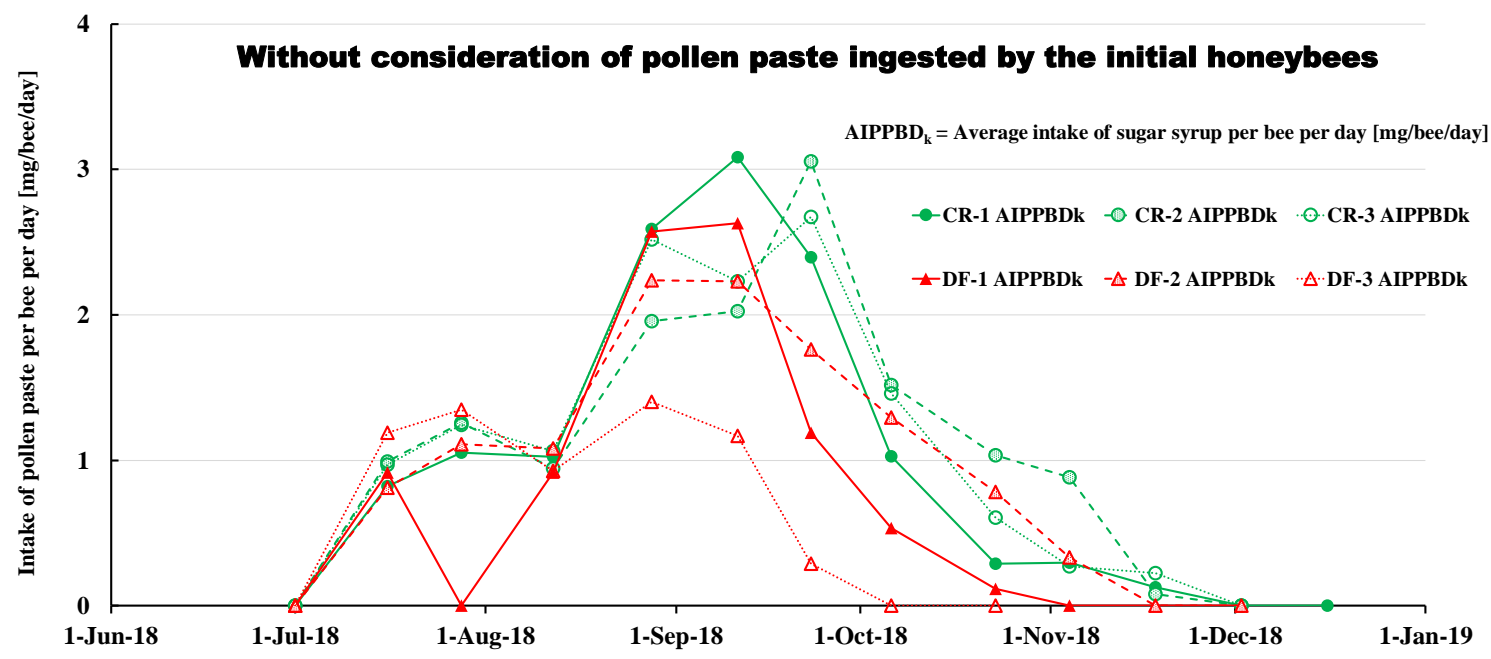

Figure 8. Average intake of pollen paste per bee per days between two adjacent measurement dates in each colony without consideration of pollen paste ingested by the initial honeybees. This figure shows the calculated intake of pollen paste (PP) per bee per day without considering the amount of PP that adult bees measured at a measurement day (initial honeybees) have already ingested till then.

- Intake of DF when Neglecting the Pre-intake of Initial Adult Bees

DF was administered to DF-exposed colony from July 1, and continued to be administered until the bee colony became extinct. On the measurement day (about once / 2 weeks), a new PP containing DF was administered, and the amount of DF ingested by bees was calculated from the consumption of PP with pesticides and the concentration of DF in PP. Incidentally, the control colony was also served every time the same amount of pesticide-free PP as the DF-exposed colony. In addition, the new $800 \mathrm{~g}$ SS of pesticide-free was also fed to all the bee colonies every time. From the experimental data obtained in this way, in two consecutive measurement days, the amount of DF to be ingested in each bee colony $\left(A I D F B_{k}\right)$ was determined. From the results, the total amount of DF ingested by the bees, from DF administration start (July 1) to the end of the experiment, was calculated. By dividing the total DF intake per bee ingested until the bee colony became extinct by the total number of adult bees involved in the DF intake (see the determination method in the previous paper [4]), was determined. These results are summarized in Table 5. The amount of DF ingested by the bees in two consecutive observation days $\left(A I D F B_{k}\right)$ is plotted in Figure 9. Further, by dividing the average intake of DF per bee in the two consecutive measurement days in the bee colony $\left(A I D A B_{k}\right)$ by the number of bees involved in DF-intake in each measurement interval (TNHBk), the average intake of DF that one bee would have consumed in one day in the measurement interval $\left(A I D A B D_{k}\right)$ [ng/bee/day] can be estimated. Intakes obtained in this way are shown in Table 6. Further, the average intake of DF 
per bee per day in the measurement interval $\left(A I D F B D_{k}\right)$ shown in Table 6 is plotted in Figure 10. From Figure 10 and Table 6, it can be seen that the followings.

Table 5. Intake of dinotefuran per colony from the start of experiment till the colony extinction without consideration of pesticide brought-in by the initial honeybees. This table shows the calculated intake of dinotefuran (DF) from the start of experiment till the colony extinction without considering the amount of DF that adult bees measured at a measurement day (initial honeybees) have already ingested till then.

\begin{tabular}{|c|c|c|c|c|c|c|}
\hline \multirow{2}{*}{$\begin{array}{c}\text { Measurement } \\
\text { date }\end{array}$} & \multicolumn{6}{|c|}{ Intake of DF per colony between two consecutive days [ $\mu \mathrm{g} /$ colony] } \\
\hline & CR-1 & CR-2 & CR-3 & DF-1 & DF-2 & DF-3 \\
\hline 19-Jun-18 & 0.0 & 0.0 & 0.0 & 0.0 & 0.0 & 0.0 \\
\hline 01-Jul-18 & 0.0 & 0.0 & 0.0 & 0.0 & 0.0 & 0.0 \\
\hline 16-Jul-18 & 0.0 & 0.0 & 0.0 & 120.0 & 120.0 & 120.0 \\
\hline 28-Jul-18 & 0.0 & 0.0 & 0.0 & 120.0 & 120.0 & 120.0 \\
\hline 12-Aug-18 & 0.0 & 0.0 & 0.0 & 120.0 & 120.0 & 120.0 \\
\hline 28-Aug-18 & 0.0 & 0.0 & 0.0 & 240.0 & 240.0 & 167.1 \\
\hline 11-Sep-18 & 0.0 & 0.0 & 0.0 & 180.0 & 211.8 & 82.4 \\
\hline 23-Sep-18 & 0.0 & 0.0 & 0.0 & 29.2 & 146.5 & 10.0 \\
\hline 06-Oct-18 & 0.0 & 0.0 & 0.0 & 7.2 & 102.0 & 0.0 \\
\hline 23-Oct-18 & 0.0 & 0.0 & 0.0 & 0.9 & 86.3 & 0.0 \\
\hline 04-Nov-18 & 0.0 & 0.0 & 0.0 & 0.0 & 12.0 & \\
\hline 18-Nov-18 & 0.0 & 0.0 & 0.0 & 0.0 & 0.0 & \\
\hline 02-Dec-18 & 0.0 & 0.0 & 0.0 & 0.0 & 0.0 & \\
\hline 16-Dec-18 & 0.0 & & & & & \\
\hline $\begin{array}{l}\text { Total intake of DF per } \\
\text { colony till colony } \\
\text { extinction [ }[\mathrm{g} / \mathrm{coloy}]\end{array}$ & 0.0 & 0.0 & 0.0 & 817.3 & 1158.6 & 619.5 \\
\hline $\begin{array}{c}\text { Total number of } \\
\text { honeybees till } \\
\text { colony extinction }\end{array}$ & 70510.2 & 81971.4 & 82090.1 & 46985.5 & 85307.2 & 59900.7 \\
\hline $\begin{array}{c}\text { Intake of DF per } \\
\text { bee till coloy } \\
\text { extiction [ng/bee] }\end{array}$ & 0.00 & 0.00 & 0.00 & 17.39 & 13.58 & 10.34 \\
\hline
\end{tabular}

Note (1): Dinotefuran pesticide (DF) was administered through pollen paste as a vehicle from July $1,2018$.

Note (2): Pesticide-free sugar syrup of $800 \mathrm{~g}$ was newly fed into all colonies every measurement date.

Note (3): Same amount of pollen paste without DF was fed into all control colonies as that with DF was fed into DF-exposed colonies.

Note (4): Same concentration and same amount of DF was administered into DF-1, DF-2 and DF-3. Note (5): Pollen paste of $300 \mathrm{~g}$ with $0.4 \mathrm{ppm}$ of DF was newly fed into every DF-exposed colony on each measurement date.

Note (6): Pollen paste of $200 \mathrm{~g}$ with $0.6 \mathrm{ppm}$ of DF was additionally fed into every DF-exposed colony on August 12, September 11 and September 23 only because we were afraid of too little intake of DF per bee. 


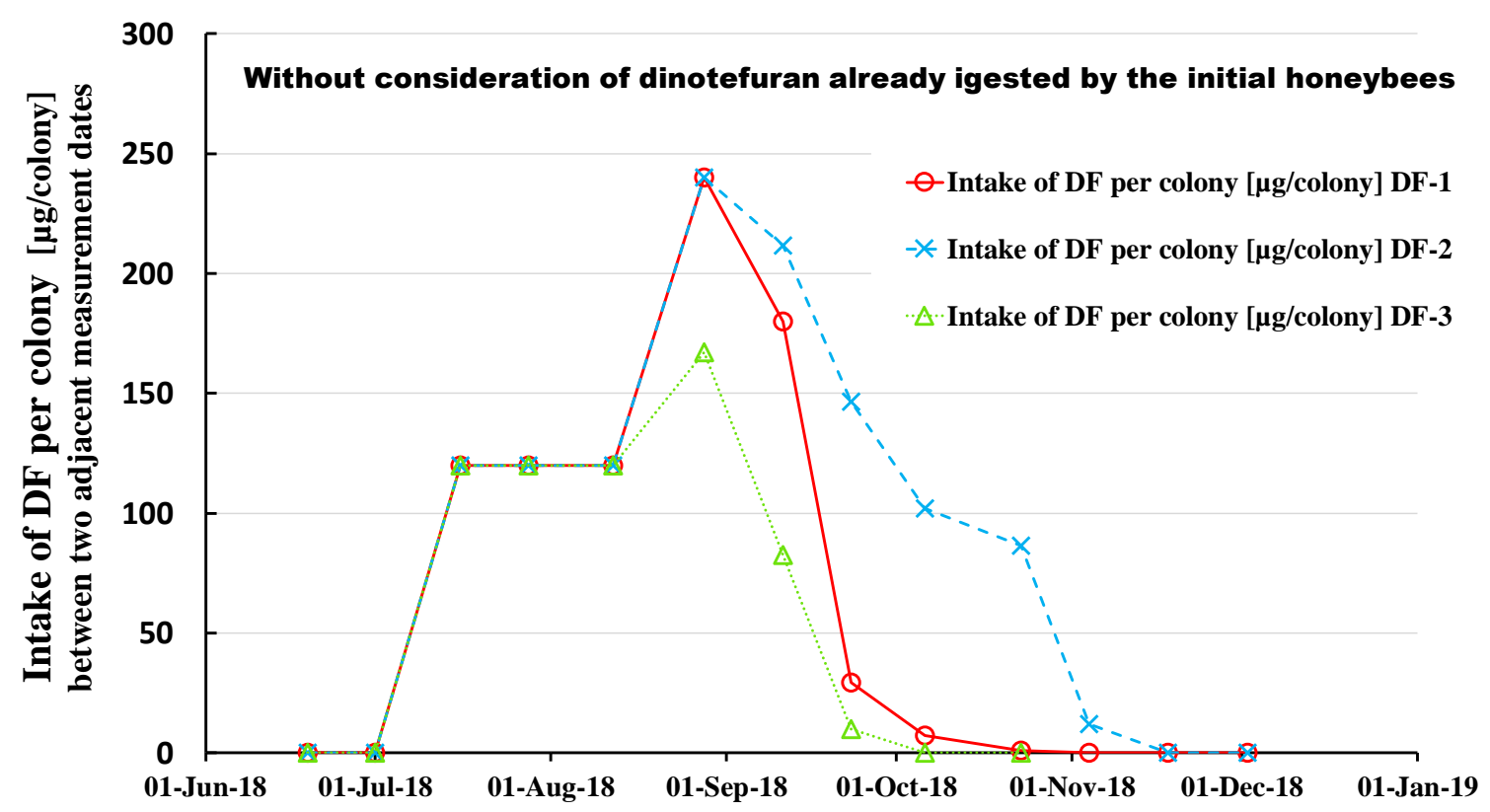

Figure 9. Intake of dinotefuran per colony without consideration of dinotefuran already ingested by the initial honeybees. This figure shows the calculated intake of dinotefuran (DF) per colony without considering the amount of DF that adult bees measured at a measurement day (initial honeybees) have already ingested till then.

Table 6. Intake of dinotefuran between two consecutive measurement days without consideration of dinotefuran already ingested by the initial honeybees. This table shows the calculated intake of dinotefuran (DF) between two consecutive measurement days without considering the amount of DF that adult bees measured at a measurement day (initial honeybees) have already ingested till then.The terms should be seen in the legends of Table 3.

\begin{tabular}{|c|c|c|c|c|c|c|c|c|c|c|c|c|c|c|}
\hline \multirow[b]{2}{*}{ Date } & \multirow[b]{2}{*}{$\mathbf{k}$} & \multirow{2}{*}{$\begin{array}{l}\Delta t_{k} \\
\text { [day] }\end{array}$} & \multicolumn{4}{|c|}{ DF-1 } & \multicolumn{4}{|c|}{ DF-2 } & \multicolumn{4}{|c|}{ DF3 } \\
\hline & & & $\begin{array}{c}\mathrm{DF}_{\mathrm{k}} \\
{[\mu \mathrm{g} / \mathrm{bee}]}\end{array}$ & $\mathrm{TNHB}_{\mathrm{k}}$ & $\begin{array}{l}\text { AIDFB }_{k} \\
\text { [ng/bee] }\end{array}$ & $\begin{array}{c}\text { AIDFBD }_{\mathbf{k}} \\
{[\text { ng/bee/day] }}\end{array}$ & \begin{tabular}{|c|}
$\mathrm{DF}_{\mathrm{k}}$ \\
{$[\mu \mathrm{g} / \mathrm{bee}]$}
\end{tabular} & $\mathrm{TNHB}_{\mathrm{k}}$ & $\begin{array}{l}\text { AIDFB }_{k} \\
\text { [ng/bee] }\end{array}$ & $\begin{array}{c}\mathbf{A I D F B D}_{\mathbf{k}} \\
{[\mathrm{ng} / \text { /bee/day] }}\end{array}$ & $\begin{array}{c}\mathrm{DF}_{\mathrm{k}} \\
{[\mu \mathrm{g} / \mathrm{bee}]}\end{array}$ & $\mathrm{TNHB}_{\mathrm{k}}$ & $\begin{array}{l}\mathbf{A I D F B}_{\mathrm{k}} \\
{[\mathrm{ng} / \mathrm{bee}]}\end{array}$ & $\begin{array}{r}\begin{array}{r}\text { AIDFBD } \\
\text { [ng/bee/day }\end{array} \\
\end{array}$ \\
\hline 19-Jun-18 & 0 & 0 & & & & & & & & & & & & \\
\hline 01-Jul-18 & 1 & 12 & 0.0 & 14901 & 0.00 & 0.00 & 0.0 & 12308 & 0.00 & 0.00 & 0.0 & 14805 & 0.00 & 0.00 \\
\hline 16-Jul-18 & 2 & 15 & 120.0 & 21864 & 5.49 & 0.37 & 120.0 & 24612 & 4.88 & 0.33 & 120.0 & 16789 & 7.15 & 0.48 \\
\hline 28-Jul-18 & 3 & 12 & 120.0 & 20430 & 5.87 & 0.49 & 120.0 & 22481 & 5.34 & 0.44 & 120.0 & 18523 & 6.48 & 0.54 \\
\hline 12-Aug-18 & 4 & 15 & 120.0 & 18043 & 6.65 & 0.44 & 120.0 & 18463 & 6.50 & 0.43 & 120.0 & 21616 & 5.55 & 0.37 \\
\hline 28-Aug-18 & 5 & 16 & 240.0 & 12140 & 19.77 & 1.24 & 240.0 & 13961 & 17.19 & 1.07 & 167.1 & 15666 & 10.67 & 0.67 \\
\hline 11-Sep-18 & 6 & 14 & 180.0 & 8153 & 22.08 & 1.58 & 211.8 & 14196 & 14.92 & 1.07 & 82.4 & 10017 & 8.23 & 0.59 \\
\hline 23-Sep-18 & 7 & 12 & 29.2 & 5111 & 5.71 & 0.48 & 146.5 & 14670 & 9.99 & 0.83 & 10.0 & 7182 & 1.39 & 0.12 \\
\hline 06-Oct-18 & 8 & 13 & 7.2 & 2587 & 2.78 & 0.21 & 102.0 & 15152 & 6.73 & 0.52 & 0.0 & 2530 & 0.00 & 0.00 \\
\hline 23-Oct-18 & 9 & 17 & 0.9 & 1113 & 0.81 & 0.05 & 86.3 & 16238 & 5.31 & 0.31 & 0.0 & 1781 & 0.00 & 0.00 \\
\hline 04-Nov-18 & 10 & 12 & 0.0 & 379 & 0.00 & 0.00 & 12.0 & 7479 & 1.60 & 0.13 & & & & \\
\hline 18-Nov-18 & 11 & 14 & 0.0 & 254 & 0.00 & 0.00 & 0.0 & 3877 & 0.00 & 0.00 & & & & \\
\hline 02-Dec-18 & 12 & 14 & 0.0 & 158 & 0.00 & 0.00 & 0.0 & 1529 & 0.00 & 0.00 & & & & \\
\hline 16-Dec-18 & 13 & 14 & & & & & & & & & & & & \\
\hline \multicolumn{3}{|c|}{$\begin{array}{l}\text { Total intake of DF per colony till } \\
\text { colony extinction [ug/coloy] }\end{array}$} & 817.3 & & & & 1158.6 & & & & 619.5 & & & \\
\hline \multicolumn{3}{|c|}{$\begin{array}{l}\text { Total number of honeybees till } \\
\text { colony extinction }\end{array}$} & & 46986 & & & & 85307 & & & & 59901 & & \\
\hline \multicolumn{3}{|c|}{$\begin{array}{l}\text { Intake of DF per bee till coloy } \\
\text { extiction [ng/bee] }\end{array}$} & & & 17.39 & & & & 13.58 & & & & 10.34 & \\
\hline \multicolumn{3}{|c|}{$\begin{array}{l}\text { Intake of DF per bee per day till } \\
\text { coloy extiction [ng/bee/day] }\end{array}$} & & & & 0.1035 & & & & 0.0808 & & & & 0.0615 \\
\hline
\end{tabular}


(1) The intake of DF ingested by each colony until the bee colony extinction, $817.3 \mu \mathrm{g} /$ colony (DF-1); $1158.6 \mu \mathrm{g} /$ colony (DF-2); $619.5 \mu \mathrm{g} /$ colony (DF-3) and the intake of DF ingested by one bee, 17.79 ng/bee (DF-1); 13.58 ng/bee (DF-2); 10.34 ng/bee (DF-3) (see Table 5). Taking the average value of the three colonies, the intake of DF per colony until is $865.1 \mu \mathrm{g} /$ colony, when expressed in the intake per bee, a $13.90 \mathrm{ng} / \mathrm{bee}$. These values are lower than the previous results of our field experiments. The reason for this, later, will be considered.

(2) The intake of DF per colony has increased rapidly since mid-August (Figure 9). The reason for this seems to be due to that even though spawning has begun toward autumn, the bee colony ingests actively PP containing DF because there are few flowers that are blooming. The amount of DF that one bee ingests per day in each measurement interval $\left(A I D F B D_{k}\right)$ is at most $1.6 \mathrm{ng} / \mathrm{bee} /$ day, in many cases $0.5 \mathrm{ng} /$ bee/day or less. In addition, the overall average intake of DF per bee per day from the DF-administration start to the colony extinction is less than $0.1 \mathrm{ng} /$ bee/day.

Incidentally, an $\mathrm{LD}_{50}$ value of the bee is usually evaluated by pesticide intake within 72 hours (3 days) (contact, oral). In this study, the overall average daily intake of DF per bee for $0.2 \mathrm{ppm}$ of administration concentration of DF is $0.1 \mathrm{ng} / \mathrm{bee} /$ day, and even for 3 days, it is $0.3 \mathrm{ng} / \mathrm{bee} / 3$ days. That value is very low compared to the $\mathrm{LD}_{50}$ value of $\mathrm{DF}$ value $(7.6-75 \mathrm{ng} / \mathrm{bee})$ for bees (see the previous paper [6]). Now, assuming that the measurement period of $\mathrm{LD}_{50}$ is 3 days and the relationship between administration concentration of pesticide and the overall average pesticide intake per bee per day is correct, If $\mathrm{LD}_{50}$ value is the lowest $(7.6 \mathrm{ng} / \mathrm{bee})$, pesticide administration concentration is estimated to be about $5 \mathrm{ppm}$.

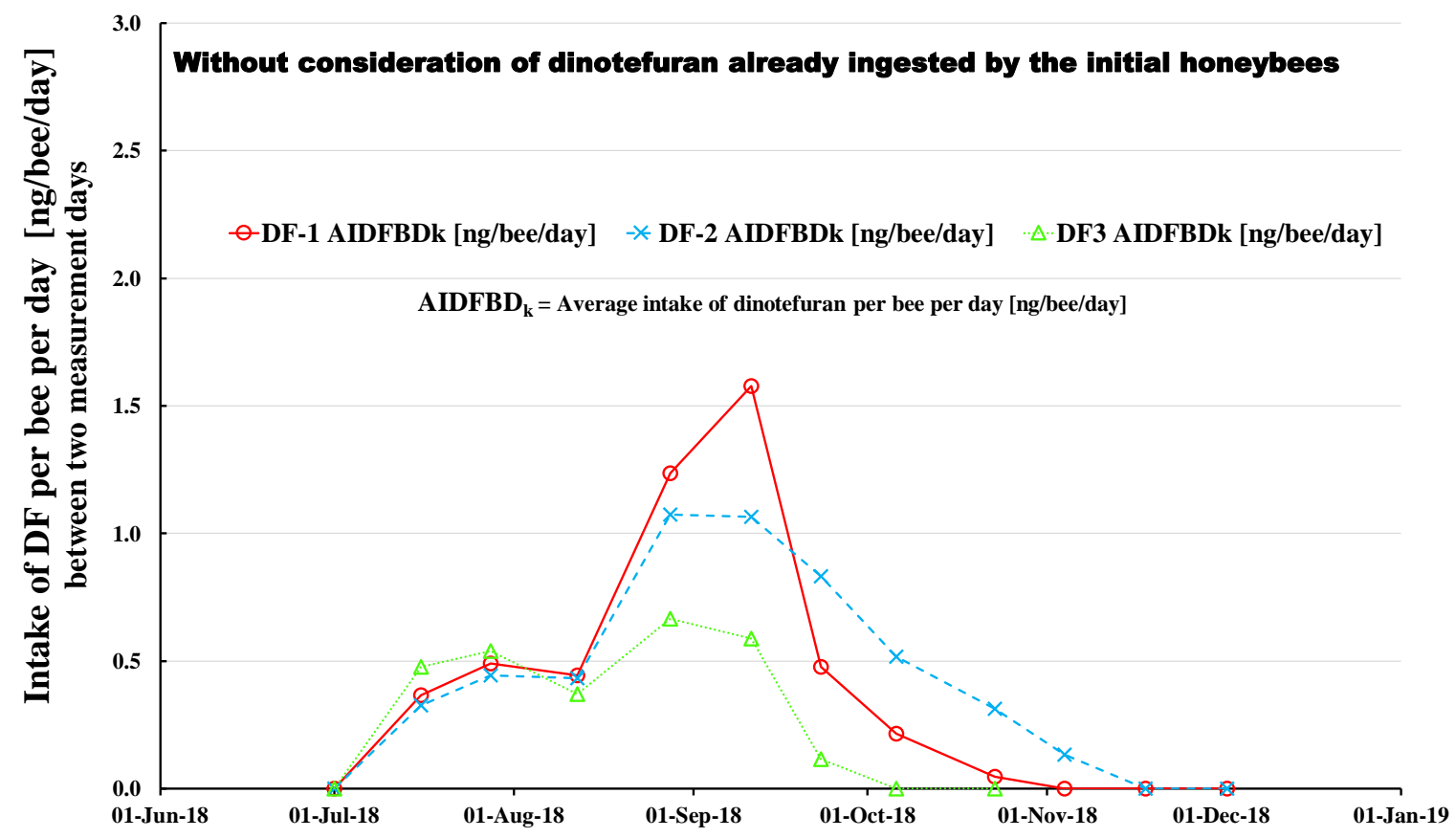

Figure 10. Intake of dinotefuran per bee per day between two adjacent measurement dates without consideration of dinotefuran already ingested by the initial honeybees. This figure shows the calculated intake of dinotefuran (DF) per bee per day without considering the amount of DF that adult bees measured at a measurement day (initial honeybees) have already ingested till then.

\subsubsection{Intakes of SS, PP and DF when Considering the Pre-intake of Adult Bees}

Adult bees measured on the $(k-1)^{\text {th }}$ measurement day (initial adult bees) is considered to have already ingested SS, PP and DF by then.

Assuming that the each intake of SS, PP and DF per bee on the the $(k-1)^{\text {th }}$ measurement day is the each average intake per bee from the $(k-2)^{\text {th }}$ measurement day to the $(k-1)^{\text {th }}$ measurement day $\left(A_{S S B D} k-1, A I P P B D_{k-1}, A I D F B D_{k-1}\right)$, each amount brought in the bee colony by the initial adult bees (pre-intake) o the kth measurement day is considered to be given by multiplying each average intake per bee between the $(k-2)^{\text {th }}$ and $(k-1)^{\text {th }}$ measurements by the number of initial adult bees on the $k^{\text {th }}$ 
measurement day. The consumption (intake) per colony between the $(k-1)^{\text {th }}$ and $k$ th measurements can be obtained by the sum of the amount brought in the colony by the initial adult bees on the ( $k$ $1)^{\text {th }}$ measurement day (pre-intake) and the consumption between the $(k-1)^{\text {th }}$ and $k$ th measurements calculated from the remaining amount measured on the $k^{\text {th }}$ measurement day. Dividing each consumption considering pre-intake $\left(S S_{k}, P P_{k}, D F_{k}\right)$ by the total number of honeybees $\left(T N H B_{k}\right)$, we can obtain the average intake of each per bee and then dividing it by the number of days between the $(k-1)^{\text {th }}$ and $k^{\text {th }}$ measurement days $\left(\Delta t_{k}\right)$, we can obtain the average intake of each per bee per day.

Considering the pre-intake of Initial adult bees and ignoring pre-intake, there was only a slight difference in each intake, and even if pre-intake was considered, the conclusion did not change with the case of ignoring pre-intake. Therefore, in this paper, the details when pre-intake is considered are omitted.

\section{Discussion}

4.1. Why did CR-1 survive longer than other bee colonies, even though the number of adult bees since midSeptember (Figure 2) and the number of capped brood (Figure 3) were less than other control colonies? Also, why did the control colony fall out before the winter?

As can be seen from Figure 5, the longest-lived CR-1 is thought to have been caused by the lowest mite-prevalence in all colonies. While most of the controls succeeded in overwintering in previous field experiments, in this experiment, it is presumed that even the control colony could not be overwintered because all bee colonies were attacked by mites before wintering (more than $80 \%$ mite-prevalence as of October).

4.2. Why did the DF-exposed colony via PP containing DF in this experiment become extinct by a lower DF intake than that in previous field experiments?

Table 7. Outline of pesticide intake in three field experiments in Shika, Japan. Location of experimental site: mid-

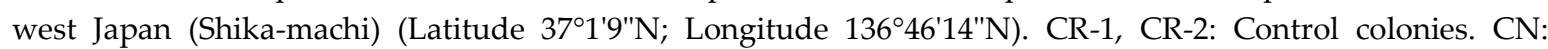
Clothianidin. DF: dinotefuran. FT: Fenitrothion. MT: Malathion. For example, "2011/2012 DF 1ppm/syrup" denotes the field experiment conducted from 2011 to 2012, where 1 ppm of dinotefuran was administered to the bee colony via sugar syrup. Bold figures denotes the field experiment where dinotefuran was administered to the bee colony via pollen paste.

\begin{tabular}{|c|c|c|c|c|c|c|c|c|}
\hline Colony name & $\begin{array}{c}\text { Initial } \\
\text { number of } \\
\text { adult bees }\end{array}$ & $\begin{array}{c}\text { Initial } \\
\text { number of } \\
\text { capped } \\
\text { brood }\end{array}$ & $\begin{array}{c}\text { Administration } \\
\text { period of pesticide }\end{array}$ & $\begin{array}{c}\text { Total intake of } \\
\text { pesticide per } \\
\text { colony during } \\
\text { administration } \\
\text { [mg/colony] }\end{array}$ & \begin{tabular}{|c} 
Total number of \\
adult bees \\
during \\
administration
\end{tabular} & $\begin{array}{c}\text { Total intake of } \\
\text { pesticide per } \\
\text { bee during } \\
\text { administration } \\
\text { [ng/bee] } \\
\end{array}$ & $\begin{array}{l}\text { Date of colony } \\
\text { extinction }\end{array}$ & $\begin{array}{c}\text { Data } \\
\text { source }\end{array}$ \\
\hline 2011/2012 CR-1 & & & & & & & Survived & [4] \\
\hline 2011/2012 DF 1ppm/syrup & 2965 & 4263 & 9-Jul-11 to 21-Oct-11 & 4.208 & 13543 & 310.7 & 21-Oct-11 & [4] \\
\hline 2011/2012 DF 10ppm/syrup & 3296 & 3880 & 9-Jul-11 to $16-J u l-11$ & 1.9 & 6344 & 290.3 & 17-Dec11 & {$[4]$} \\
\hline 2011/2012 DF 5.65 ppm/pollen & 1659 & 6993 & 9-Jul-11 to 16-Jul-11 & 0.5257 & 3078 & 65.1 & $16-J u l-11$ & {$[4]$} \\
\hline 2012/2013 CR-1 & & & & & & & Survived & [5] \\
\hline $2012 / 2013$ CR-2 & & & & & & & Survived & {$[5]$} \\
\hline 2013/2014 CR-1 & & & & & & & 7-Frb-14 & {$[6]$} \\
\hline 2013/2014 CR-2 & & & & & & & Survived & {$[6]$} \\
\hline 2013/2014 DF 0.2ppm/syrup & 6017 & 2214 & 5-Sep-13 to 1-Dec-13 & 0.514 & 8612 & 56.7 & 5-Jan-14 & {$[6]$} \\
\hline 2013/2014 CN 0.08ppm/syrup & 7293 & 1506 & 5-Sep-13 to 1-Dec-13 & 0.4016 & 10130 & 39.6 & 5-Jan-14 & {$[6]$} \\
\hline 2013/2014 FT 1ppm/syrup & 10296 & 3232 & 5-Sep-13 to 28 -Feb-14 & 3.86 & 19585 & 197.1 & 28-Feb-14 & {$[6]$} \\
\hline 2013/2014 MT 1ppm/syrup & 7676 & 1396 & 5-Sep-13 to 7-Feb-14 & 6.75 & 15724 & 429.3 & 7-Feb-14 & {$[6]$} \\
\hline
\end{tabular}


Table 7 summarizes the pesticide intake of long-term field experiments that we have conducted so far. From Table 7, it can be seen that the intake of DF per bee whose colony became extinct by administering PP containing DF is $60-65 \mathrm{ng} /$ bee $(0.274-2.324 \mathrm{ng} / \mathrm{bee} / \mathrm{day})$ in previous field experiments (see the bee colonies highlighted in the red in the table: 2011/2012 DF 0.565ppm/pollen \& 2011/2012 DF 5.65ppm/pollen). In this study, however, the DF-exposed colony has become extinct by a fairly small intake at 10-18 ng/bee (average: $14 \mathrm{ng} / \mathrm{bee}$ ). This is estimated to have caused the attacks of mites and Japanese giant hornets to collapse the bee colony with less DF intake than before. It should be noted that, since the DF-exposed colony via toxic PP in this study has become extinct earlier than the control colony, it cannot be denied that DF contained in PP also adversely affects the bee colony. Further, judging from the fact that the mite-prevalence is higher towards the DF-exposed colony than the control colony, DF contained in PP is considered to be accelerating the spread of mites. That is, it is considered that the bee colony weakened by DF contained in PP was accelerated the spread by being attacked by mites. This supports the hypotheses that we have previously published [1].

\section{Conclusions}

The negative synergistic effect on bee colonies between DF and Varroa mites is observed from the facts that DF-exposed colonies where DF was administered via pollen paste had smaller number of adult bees and became extinct earlier than control (pesticide-free) colonies and although queen bees of DF-exposed colonies were lost in the middle of the experiment, those of control colonies were present in until the time of extinction. The rapid decrease in the number of capped brood in October is different from the usual situation in which the number of capped brood begins to decrease around November. This seems to be due to the attacks of Japanese giant hornets and the spread of mites.

From the fact that the daily sugar-syrup (pesticide-free) intake of one bee in the DF-exposed colony administered via pollen paste is greater than that of the control colony, DF may probably have an appetite-promoting effect. It is speculated that DF excites bees and increases the activity of ingestion.

The consumption of sugar syrup in one bee from the start of the DF administration to the extinction of the bee colony is almost $80 \mathrm{mg} /$ bee, regardless of the DF-exposed colony and the control colony, except for DF-1, where the queen bee was lost early.

Since the amount of DF-containing pollen paste that one bee consumes in a day is almost no difference between DF-exposed colonies where DF was administered via pollen paste and control colonies, DF seems to have no repellent effect.

The amount of pollen paste consumed by one bee from the start of DF administration to the extinction of bee colonies, regardless of the distinction between DF-exposed colonies and control colonies, is 25 to $35 \mathrm{mg} / \mathrm{bee}$. The amount of DF per bee from the start of DF administration to the extinction of bee colonies is $10-18 \mathrm{ng} / \mathrm{bee}$, and the daily intake of one bee is $0.1 \mathrm{ng} / \mathrm{bee} /$ day or less. Judging from the fact that the amount of DF per bee from the start of DF administration to the extinction of bee colonies is $60-65 \mathrm{ng} / \mathrm{bee}$ in the $2011 / 2012$ experiment [ 4 ] and that is $10-18 \mathrm{ng} / \mathrm{bee}$ in this work, the damage by mites will greatly promote the colony extinction.

According to the seasonal change in mite-prevalence, even if the number of mite-damaged bees turns to decrease, mite-prevalence continues to rise, and becomes almost $100 \%$ at the time of bee colony extinction. Increase in mite-prevalence will be due to the rate of the decrease in the total number of adult bees is higher than the rate of decrease in the number of mite-damaged bees. The number of mite-damage bees in the bee colony does not change in order since the beginning of October, with CR-2 $>$ DF-2 $>$ CR-3 $>$ CR-1 $>$ DF- $1>$ DF-3, this order is the same as the order of the number of capped brood at this time. This can be understood from the increase in mites by parasitic on larvae in the bee colony.

Based on the fact that mite-prevalence of honeybees increases rapidly from the beginning of September (Figure 5) and the apparent longevity of adult bees begins to increase around the end of 
September [46], it may be effective to exterminate Varroa mites for bee larvae in early autumn (early September) when preparations of wintering have be started.

The fluctuation range of the inner temperature of the hive-box $\left(\mathrm{T}_{\mathrm{i}}\right)$ is smaller than that of the ambient temperature of the hive-box $\left(T_{a}\right)$. The fluctuation range of the inner temperature of the DFexposed colony hive-box is larger than that of the control colony hive-box. $\mathrm{T}_{\mathrm{i}}$ seems to be controlled with about $30{ }^{\circ} \mathrm{C}$ of $\mathrm{T}_{a}$ as the boundary. If $\mathrm{T}_{\mathrm{a}}$ is $30^{\circ} \mathrm{C}$ or less, $\mathrm{T}_{\mathrm{i}}$ becomes higher than $\mathrm{T}_{\mathrm{a}}$, if $\mathrm{T}_{\mathrm{a}}$ is $30{ }^{\circ} \mathrm{C}$ or more, $\mathrm{T}_{\mathrm{i}}$ is lower than $\mathrm{T}_{\mathrm{a}}$.

In this study, it was found that the bee colony was collapsed by the intake of a smaller amount of DF due to the synergistic effect of DF, one of the neonicotinoid pesticides, and mite-damage. To prevent a bee colony collapse, not only to make an effort to minimalize the adverse effect on the bee colony of neonicotinoids with long-term residual effect and high insecticide properties, it is necessary to reduce the damage of mites as much as possible.

In this paper I have reported the seasonal change in the bee colony size and mite-prevalence of the dinotefuran-exposed and mite-damaged honeybee colony. This study found that not only neonicotinoids but also Varroa mites could adversely affect the honeybee colony.

In the near future, we will investigate the seasonal change in the apparent longevity whose mathematical model was proposed previously [46], for the DF-exposed \& Varroa-mite-damaged colony where DF was administered via pollen paste, using the numbers of adult bees and capped brood measured accurately in this work.

Supplementary Materials:, Figure S1: The inside of the hive box is numbered clockwise from the face of the entrance, Figure S2: An example of numbered comb frame, Figure S3: Photo stand, two empty hive-boxes, experiment $\log$ and beekeeping tools, Figure S4: Overall view of experimental site, Method S1: Field experimental procedures, Method S2: Determination procedure of the numbers of adult bees and capped brood, Method S3: Criteria for determining mite-damaged bees and estimating the number of mite-damaged bees, Table S1: Summary of experimental conditions and results of four long-term field experiments in Shika, Japan, Table S2: Weather information \& Experimental time, Table S3: Summary of observational results for control colonies (CR-1; CR-2; CR-3), Table S4: Summary of observational results for DF-exposed colonies (DF-1; DF-2; DF-3), Table S5: Summary of experimental note.

Author Contributions: Toshiro Yamada conceived and designed the experiments, performed the experiments, analyzed the data, prepared figures and/or tables, authored or reviewed drafts of the paper, and approved the final draft.

Funding: This research was funded by a Yamada Research Grant (grant number 253) of Yamada Bee Farm Inc. at https://www.bee-lab.jp/grant/grant/qa.html.

Acknowledgments: In field experiments, it is very important not only whether to experiment carefully, but also whether to count the number of adult bees, the number of capped brood and the number of mite-damaged bees, with high accuracy. I would like to express my deep gratitude to members (Mr. Tetsuya Kojima, Ms. Yuki Kojima, Dr. Hiroshi Mibayashi, Ms. Kimiko Mimura-Ruth and Mr. Kenji Mimura) of YUINOTE, which is a natural farming group in Noto, Japan, for taking a lot of effort and time to cooperate with the implementation of this field experiment and the counting of the numbers of adult bees and capped brood. I am indebted to Ms. Kazuko Yamada for her cooperation in the experiment. I would also like to express my deep gratitude to $\mathrm{Mr}$. Yuhki Nagai (Nanosystem Co., Ltd., Kyoto, Japan) for developing and improving automatic counting software to speed up the count of adult bee numbers, number of capped brood, and number of damaged mites. In carrying out this research, Dr. Ken Hashimoto (Yamada Bee Farm, Inc., Okayama, Japan) gave me warm advice and encouragement. Thank you deeply here.

Conflicts of Interest: The authors declare no conflict of interest. The funders had no role in the design of the study; in the collection, analyses, or interpretation of data; in the writing of the manuscript, or in the decision to publish the results. 


\section{References}

1. Yamada, T.; Yamada, K.; Wada, N. Influence of dinotefuran \& clothianidin on a bee colony. Jpn. J. Clin. Ecol. 2012, 21(1), 10-23. Available online: https://pdfs.semanticscholar.org/3f80/aaf45ee1e189ab8fbd16b0428ac667a0f9f5.pdf (accessed on 10 October 2020).

2. Lu, C.; Warchol, K.M.; Callahan, R.A. In situ replication of honeybee colony collapse disorder. B. Insectol. 2012, 65(1), 99-106. Available online: https://citeseerx.ist.psu.edu/viewdoc/download?doi=10.1.1.692.8827\&rep=rep1\&type=pdf.

3. Matsumoto, T. Short- and long-term effects of neonicotinoid application in rice fields, on the mortality and colony collapse of honeybees (Apis mellifera). J. Apic. Sci. 2013, 57(2), 21-35.

4. Yamada, T.; Yamada, K.; Yamada, Y. A clear difference in the impact on honeybee (Apis mellifera) colony between the two vehicles of sugar syrup and pollen paste. J. Biol. Ser. 2018a, 1(3), 084-107. DOI 10.15413/jbs.2018.0400. Available online: https://www.academiapublishing.org/journals/jbs/abstract/2018/Jul/Toshiro\%20et\%20al.htm.

5. Yamada, T.; Yamada, Y.; Yamada, K. Difference between the impact of the neonicotinoid dinotefuran and organophosphate fenitrothion on a bee colony in a long-term field experiment: An evidence. J. Biol. Ser. 2018b, 1(3), 108-137 DOI: 10.15413/jbs.2018.0401. Available online: https://www.academiapublishing.org/journals/jbs/abstract/2018//Jul/Yamada\%20et\%20al.htm.

6. Yamada, T.; Yamada, Y.; Yamada, K. Comparison of the influence of a pesticide at an environmentally realistic concentration level in Japan on a honeybee colony between neonicotinoids (dinotefuran, clothianidin) and organophosphates (fenitrothion, malathion). J. Biol. Ser. 2018, 1(4), 187-207. DOI: 10.15413/jbs.2018.0402. Available online: https://www.academiapublishing.org/journals/jbs/abstract/2018/Oct/Yamada\%20et\%20al.htm.

7. Yamada, T.; Yamada, K.; Apao, P. Comparison of the long-term influence of a pesticide on a bee colony between neonicotinoids (dinotefuran, clothianidin) and organophophate (fenitrothion) in Maui where there are neither harmful mites nor cold winter. J. Biol. Ser. 2018, 1(4), 156-186. DOI: 10.15413/jbs.2018.0403. Available online: https://www.academiapublishing.org/journals/jbs/abstract/2018/Oct/Yamada\%20et\%20al..htm.

8. Yamada, T.; Yamada, K. Comparison of long-term changes in size and longevity of bee colonies in midwest Japan and Maui with and without exposure to pesticide, cold winters, and mites. PeerJ 2020, 8, e9505. Available online: https://doi.org/10.7717/peerj.9505.

9. Lu, C.; Warchol, K.M.; Callahan, R.A. Sub-lethal exposure to neonicotinoids impaired honey bees winterization before proceeding to colony collapse disorder. B. Insectol. 2014, 67(1), 125-130. Available online: https://www.semanticscholar.org/paper/Sub-lethal-exposure-to-neonicotinoids-impaired-bees-LuWarchol/c6d0134af1636110aeb9122d51d5ff3c5b0b16b2.

10. Wilfert, L.; Long, G.; Leggett, H.C.; Schmid-Hempel, P.; Butlin, R.K.; Martin, S.J.; Boots, M. Deformed wing virus is a recent global epidemic in honeybees driven by Varroa mites. Science 2016, 351(6273), 594-597. DOI: 10.1126/science.aac9976. Available online: https://science.sciencemag.org/content/351/6273/594.

11. Dainat, B.; Evans, J.D.; Chen, Y.P.; Gauthier, L.; Neumann, P. Dead or Alive: Deformed Wing Virus and Varroa destructor Reduce the Life Span of Winter Honeybees. Appl. Environ. Microb. 2012, 78(4), 981-987. DOI: 10.1128/AEM.06537-11.

12. Pinto, F.A.; Puker, A.; Barreto, L.M.R.C.; Message, D. The ectoparasite mite Varroa destructor Anderson and Trueman in southeastern Brazil apiaries: effects of the hygienic behavior of Africanized honey bees on infestation rates. Arquivo Brasileiro de Medicina Veterinária e Zootecnia (Brazilian Journal of Veterinary and Animal Science) 2012, 64(5), 1194-1199. Available online: https://www.scielo.br/pdf/abmvz/v64n5/v64n5a17.pdf.

13. Strauss, U.; Pirk, C.W.W.; Crewe, R.M.; Human, H.; Dietemann, V. Impact of Varroa destructor on honeybee (Apis mellifera scutellata) colony development in South Africa. Exp. Appl. Acarol. 2015, 65(1), 89-106. DOI 10.1007/s10493-014-9842-7. Available online: https://link.springer.com/article/10.1007/s10493-014-9842-7.

14. Reyes-Quintana, M.; Espinosa-Montaño, L.G.; Prieto-Merlos, D.; Koleoglu, G.; Petukhova, T.; CorreaBenítez, A.; Guzman-Novoa, E. Impact of Varroa destructor and deformed wing virus on emergence, cellular immunity, wing integrity and survivorship of Africanized honey bees in Mexico. J. Invertebr. Pathol. 2019, 164, 43-48. Available online: https://doi.org/10.1016/j.jip.2019.04.009. 
15. Barroso-Arévalo, S.; Fernández-Carrión, E.; Goyache, J.; Molero, F.; Puerta, F.; Sánchez-Vizcaíno, J.M. High Load of Deformed Wing Virus and Varroa destructor Infestation Are Related to Weakness of Honey Bee Colonies in Southern Spain. Front. Microbiol. 2019, 14, 1-8. Available online: https://doi.org/10.3389/fmicb.2019.01331.

16. Ayoub, Z.N. Virulence of Varroa destructor in Colonies of Honey Bee Apis mellifera. Beekeeping - New Challenges, Ramón Eduardo Rebolledo Ranz, IntechOpen. 2020. DOI: 10.5772/intechopen.81018. Available online: $\quad$ https://www.intechopen.com/books/beekeeping-new-challenges/virulence-of-em-varroadestructor-em-in-colonies-of-honey-bee-em-apis-mellifera-em-.

17. Highfield, A.C; Nagar, A.E; Mackinder, L.C.M; Noël, L.M-L.J.; Hall, M.J.; Martin, S.J.; Schroeder, D.C. Deformed Wing Virus Implicated in Overwintering Honeybee Colony Losses. Appl. Environ. Microb. 2009, 75(22), 7212-7220. DOI10.1128/AEM.02227-09.

18. Le Conte, Y.; Ellis, M.; Ritter, W. Varroa mites and honey bee health: can Varroa explain part of the colony losses? Apidologie 2010, 41 (3), 353-363. DOI: 10.1051/apido/2010017. Available online: https://www.apidologie.org/articles/apido/full html/2010/03/m09176/m09176.html.

19. Schroeder, D.C.; Martin, S.J. Deformed wing virus: The main suspect in unexplained honeybee deaths worldwide. Virulence 2012, 3(7), 589-591. DOI 10.4161/viru.22219. Available online: https://doi.org/10.4161/viru.22219.

20. Francis, R.M.; Nielsen, S.L.; Kryger, P. Varroa-Virus Interaction in Collapsing Honey Bee Colonies. PLoS One 2013, 8(3), e57540. DOI 10.1371/journal.pone.0057540.

21. Alvarez-Ventura, S.C. Measuring Impacts of Neem Oil and Amitraz on Varroa destructor and Apis Mellifera in Different Agricultural Systems of South Florida. FIU Electronic Theses and Dissertations 490. M.Sc. Thesis, Florida International University. September 2011. DOI: 10.25148/etd.FI11120503. Available online: https://digitalcommons.fiu.edu/etd/490.

22. Abou-Shaara H. Continuous management of Varroa mite in honey bee, Apis mellifera, colonies. Acarina 2014, 22(2), 149-156.

23. Aziz, M.A.; Azeem, M.; Ahmed, M.S.; Siddique, F.; Jamal, M. Control of Varroa Destructor Anderson and Trueman (Acari: Varroidae) on Apis Mellifera Linguistica by Using Thymol and Formic Acid in Pothwar Region of Punjab, Pakistan. Asian J. Agric. \& Biol. 2015, 3(4), 150-154.

24. Riusech, N.S. Varroa mite control in honey bee colonies: The use of a fatty acid blend (C8910) for Varroa mite control and exploring management practices used by beekeepers. M.Sc. Thesis, The Ohio State University. 2017 Available online: https://etd.ohiolink.edu/pg_10?0::NO:10:P10_ACCESSION_NUM:osu1492683874951262.

25. Harris, J.; Sheridan, A.B.; MacGown, J.A. Managing Varroa Mites in Honey Bee Colonies. The Mississippi State University Extension Service Publication Number: P2826 (POD-06-19). 2019. Available online: http://extension.msstate.edu/sites/default/files/publications/publications/p2826 web.pdf.

26. Underwood, R.; López-Uribe, M. Methods to Control Varroa Mites: An Integrated Pest Management Approach. PennState Extension, updated on May 23, 2019, PP. 1-4, The Pennsylvania State University. Available online: https://extension.psu.edu/methods-to-control-varroa-mites-an-integrated-pestmanagement-approach.

27. Gajger, I.T; Svečnjak, L.; Bubalo, D,.; Žorat T. Control of Varroa destructor Mite Infestations at Experimental Apiaries Situated in Croatia. Diversity 2020, 12(1), 12. DOI 10.3390/d12010012. Available online: https://www.mdpi.com/1424-2818/12/1/12.

28. Hood, W.M. The small hive beetle, Aethina tumida: a review. Bee World 2004, 85(3), 51-59. DOI: 10.1080/0005772X.2004.11099624. Available online: https://doi.org/10.1080/0005772X.2004.11099624.

29. Cuthbertson, A.G.S; Wakefield, M.E.; Powell, M.E.; Marris, G.; Anderson, H.; Budge, G.E.; Mathers, J.J.; Blackburn, L.F.; Brown, M.A. The small hive beetle Aethina tumida: A review of its biology and control measures. Curr. Zool. 2013, 59(5), 644-653. Available online: https://doi.org/10.1093/czoolo/59.5.644.

30. Mutinelli, F.; Montarsi, F.; Federico, G.; Granato, A.; Ponti, A.M.; Grandinetti, G.; Ferrè, N.; Franco, S.; Duquesne, V.; Rivière, M-P.; Thiéry, R.; Henrikx, P.; Ribière-Chabert, M.; Chauzat, M-P. Detection of Aethina tumida Murray (Coleoptera: Nitidulidae.) in Italy: outbreaks and early reaction measures. J. Apicult. Res. 2014, 53(5), 569-575. DOI: 10.3896/IBRA.1.53.5.13. Available online: https://doi.org/10.3896/IBRA.1.53.5.13.

31. Neumann, P.; Pettis, J.S.; Schäfer, M.O. Quo vadis Aethina tumida? Biology and control of small hive beetles. Apidologie 2016, 47, 427-466. DOI https://doi.org/10.1007/s13592-016-0426-x. Available online: https://doi.org/10.1007/s13592-016-0426-x. 
32. Al Toufailia, H.; Alves, D.A.; Bená, D.D.C.; José, M.S.; Bento, J.M.S.; Iwanicki, N.S.A.; Cline, A.R.; Ellis, J.D.; Ratnieks, F.L.W. First record of small hive beetle, Aethina tumida Murray, in South America. J. Apicult. Res. 2017, 56(1), 76-80. Available online: https://doi.org/10.1080/00218839.2017.1284476.

33. Schäfer, M.O.; Cardaio, H.; Cilia, G.; Cornelissen, B.; Crailsheim, K.; Formato, G.; Lawrence, A.K.; Le Conte, Y.; Mutinelli, F.; Nanetti, A.; Rivera-Gomis, J.; Teepe, A.; Neumann, P. How to slow the global spread of small hive beetles, Aethina tumida. Biol. Invasions 2019, 21, 1451-1459. Available online: https://doi.org/10.1007/s10530-019-01917-x.

34. Powell, M.E.; Bradish, H.M.; Cao, M.; Makinson, R.; Brown, A.P.; Gatehouse, J.A.; Fitches, E.C. Demonstrating the potential of a novel spider venom-based biopesticide for target-specific control of the small hive beetle, a serious pest of the European honeybee. J. Pest. Sci. 2020, 93, 391-402. DOI https://doi.org/10.1007/s10340-019-01143-3. Available online: https://link.springer.com/article/10.1007/s10340-019-01143-3.

35. Kwadha, C.A.; Ong'amo, G.O.; Ndegwa, P.N.; Raina, S.K.; Fombong, A.T. The Biology and Control of the Greater Wax Moth, Galleria mellonella. Insects 2017, 8, 61: 1-17. Available online: https://doi.org/10.3390/insects8020061.

36. Lalita; Kumar, Y.; Yadav, S. Seasonal incidence of Greater wax moth, Galleria mellonella Linnaeus in Apis mellifera colonies in ecological condition of Hisar. J. Entomol. Zool. Stud. 2018, 6(1), 790-795.

37. Vijayakumar, K.T,; Neethu, T.; Shabarishkumar, S.; Nayimabanu Taredahalli; Madhu, K.V.; Bhat, N.S.; Kuberappa, G.C. Survey, biology and management of greater wax moth, Galleria mellonella L. in Southern Karnataka, India. J. Entomol. Zool. Stud. 2019, 7(4), 585-592. Available online: http://www.entomoljournal.com/archives/2019/vol7issue4/PartJ/7-4-66-689.pdf.

38. Mathialagan, M.; Johnson Thangaraj Edward, Y.S.; David, P.M.M. Wax Moth Infestation and its Management in Indian Honey bee, Apis cerana F. Colonies in Tamil Nadu. Madras Agric. J., 2019, 106(4-6), 400-405. DOI 10.29321/MAJ 2019.000282.

39. Negi, N.; Thakur, M.; Sharma, H.K.; Rana, K. Incidence and management of greater wax moth, Galleria mellonella. J. Entomol. Res. 2019, 43(2), 139-143. DOI 10.5958/0974-4576.2019.00027.6.

40. Li, Y.; Jiang, X.; Wang, Z.; Zhang, J.; Klett, K.; Mehmood, S.; Qu, Y.; Tan, K. Losing the Arms Race: Greater Wax Moths Sense but Ignore Bee Alarm Pheromones. Insects 2019, 10(3), 81. DOI 10.3390/insects10030081. Available online: https://doi.org/10.3390/insects10030081.

41. Beaurepaire, A.; Piot, N.; Doublet, V.; Antunez, K.; Campbell, E.; Chantawannakul, P.; Chejanovsky, N.; Gajda, A.; Heerman, M.; Panziera, D.; Smagghe, G.; Yañez, O.; de Miranda, JR.; Dalmon, A. Diversity and Global Distribution of Viruses of the Western Honey Bee, Apis mellifera. Insects 2020, 11(4), 239. Available online: https://www.mdpi.com/2075-4450/11/4/239.

42. Roberts, J.M.K.; Denis, L.; Anderson, D.L.; Durr, P.A. Absence of deformed wing virus and Varroa destructor in Australia provides unique perspectives on honeybee viral landscapes and colony losses. Sci. Rep. 2017, 7, 6925. Available online: https://doi.org/10.1038/s41598-017-07290-w.

43. Strange, J.P.; Sheppard, W.S. Optimum Timing of Miticide Applications for Control of Varroa destructor (Acari: Varroidae) in Apis mellifera (Hymenoptera: Apidae) in Washington State, USA. J. Econ. Entomol. 2001, 94(6): 1324-1331. Available online: https://academic.oup.com/jee/articleabstract/94/6/1324/2217499?redirectedFrom=fulltext.

44. Macedo, P.A.; Wu, J.; Ellis, M.D. Using inert dusts to detect and assess varroa infestations in honey bee colonies. J. Apicult. Res. 2002, 41(1-2), 3-7. Available online: https://www.tandfonline.com/doi/abs/10.1080/00218839.2002.11101062.

45. Barlow, V.M.; Fell, R.D. Sampling Methods for Varroa Mites on the Domesticated Honeybee. Virginia Cooperative Extension publication number: 444-103. 2006. Available online: https://vtechworks.lib.vt.edu/bitstream/handle/10919/50392/444-103.pdf?sequence=1.

46. Yamada Y, Yamada T. Yamada K. A mathematical model for estimation of long-term change in apparent longevity of honeybee colony. Sci. Rep. 2019, 9, 4102. Available online: https://www.nature.com/articles/s41598-019-40725-0. 